Gerión. Revista de Historia Antigua

ISSN: 0213-0181

http://dx.doi.org/10.5209/GERI.60296

\title{
La conquête de l'Afrique romaine par les Vandales (429-439 après J.-C.)
}

\author{
Yann Le Bohec ${ }^{1}$
}

Recibido: 17 de mayo de 2017 / Aceptado: 9 de enero de 2018

Résumé. Menacés par l'arrivée des Goths et attirés par la prospérité de l'Afrique, une région militairement mal défendue, les Vandales traversèrent le détroit de Gibraltar. Arrivés sur leur nouvelle terre, ils remportèrent une première bataille en rase campagne, mais ils connurent des difficultés pour prendre Hippone. Ensuite, ils vainquirent une deuxième fois en plaine, à l'est d'Hippone, puis ils s'emparèrent de Carthage, par ruse.

Mots-clefs: bataille; Carthage; Hippone; stratégie; tactique; siège.

\section{[en] The conquest of Roman Africa by the Vandals (429-439 AD)}

\begin{abstract}
Under the threat of the Goths, who arrived from Gaul, and feeling that Africa was attractive, because of its wealth, the Vandals crossed over the strait of Gibraltar. Arrived on this land, they fought victoriously in a first battle, but they met some difficulties during the siege of Hippo Regius. Then, they were again victorious on land. Finally, they entered in Carthage, by treason.
\end{abstract}

Keywords: Battle; Carthage; Hippo Regius; Strategy; Tactics; Siege.

Sommaire. 1. Les Vandales et l'Afrique. 2. La traversée du détroit (429). 3. Les forces en présence 1: l'armée vandale. 3.1. L'efficacité. 3.2. Les effectifs. 3.3. L'encadrement. 3.4. Les armes. 3.5. L'équipement. 3.6. La poliorcétique. 4. Les forces en présence 2: l'armée romaine. 4.1. L'efficacité. 4.2. La hiérarchie. 4.3. Les effectifs. 4.4. Les unités. 4.5. La poliorcétique et la stratégie. 4.6. Les mythes et les faux-problèmes. 5. La progression des Vandales (429-431). 5.1. La marche vers l'est. 5.2. Une bataille en rase campagne. 5.3. Le siège d'Hippone. 5.4. Une deuxième bataille en rase campagne. 6. Les dégâts causés par les Vandales. 6.1. Le problème. 6.2. Les méfaits. 7. La progression des Vandales (430-439). 7.1. La "diplomatie". 7.2. La prise de Carthage. 8. Conclusion. 9. Bibliographie.

Cómo citar: Le Bohec, Y. (2018): La conquête de l'Afrique romaine par les Vandales (429-439 après J.-C.), en Gerión 36/1, 109-140.

\footnotetext{
1 Université Paris-Sorbonne (Paris IV).

E-mail: yann.lebohec@wanadoo.fr
} 
Beaucoup de bons travaux ont été récemment consacrés aux Vandales, à leur histoire en général et à leur présence dans la péninsule Ibérique en particulier; il est donc inutile de revenir sur ces deux sujets. ${ }^{2}$ En revanche, leur action proprement militaire en Afrique, même si elle a été abordée, très peu au demeurant, mérite d'être approfondie. ${ }^{3}$ Nous proposons donc de faire de l'histoire militaire dans le cadre de la Völkerwanderung, et d'aborder deux domaines essentiels à cet égard, la stratégie et la tactique. Les Romains ont-ils conçu une stratégie défensive ou en ont-ils été incapables? Si oui, fut-elle réellement une stratégie en profondeur? Et, toujours si une stratégie romaine a bien été appliquée, quelle contre-stratégie les Vandales ont-ils mise en jeu? Quelles étaient les forces en présence? Les assaillants ont-ils été meilleurs dans la bataille en rase campagne, dans la poliorcétique? Et ont-ils pratiqué d'autres formes de combats?

\section{Les Vandales et l'Afrique}

Le nom de Vandales recouvre en réalité plusieurs peuples très majoritairement de langue germanique qui se sont agglomérés les uns aux autres au fil des siècles et qui se sont soumis les uns les autres à des influences réciproques. Les archéologues les identifient plus clairement à partir du moment où ils peuvent être caractérisés par des traits qui définissent ce qu'ils appellent la culture de la Tisza. ${ }^{4}$ Pour notre propos, ils sont devenus importants dans la nuit du 31 décembre 406, quand ils ont franchi le Rhin en plusieurs endroits, accompagnés surtout par des Suèves, d'autres Germains, et par des Alains, des iranophones. De 406 à 409, ils ont séjourné en Gaule; une tradition récente peint ce passage sous des couleurs apaisées; nous croyons au contraire qu'ils s'y sont conduits avec brutalité. ${ }^{5}$ Puis ils sont passés dans la péninsule Ibérique où ils sont restés de 409 à 429 , toujours avec le même comportement cruel. ${ }^{6}$

Pour la tactique et la stratégie, les sources sur lesquelles doit s'appuyer une enquête sont peu nombreuses, comme il arrive souvent quand il s'agit de l'Antiquité, et elles se limitent à quelques textes; ${ }^{7}$ l'archéologie, la numismatique et l'épigraphie seront utilisées plus loin, mais leur apport pour le sujet est modeste. Les passages utiles seront mentionnés plus loin, dans les notes infra-paginales; ici, nous ne recherchons pas l'exhaustivité sur ce peuple lui-même, et des additions peuvent être trouvées dans un article aujourd'hui un peu ancien. ${ }^{8}$

Les Vandales eux-mêmes n'ayant pas laissé d'écrits, les deux principaux auteurs appartenaient au monde des Romains. Victor de Vita, un Africain qui a rédigé une

2 Des références seront proposées dans les notes suivantes. Pour une enquête exhaustive sur la bibliographie, voir la Bibliographie analytique de l'Afrique antique, compilée pendant longtemps par l'auteur de cet article.

3 Travail récent et superficiel: Lusvarghi 2016.

$4 \quad$ Berndt - Steinacher, éds., 2008; Merrills - Miles 2010, 31-33; Vössing 2015; MacDowall 2016. Voir Pingel 2006, et notes suiv.

$5 \quad$ Le Bohec 2007.

6 Très abondante bibliographie; retenons, en dernier lieu, à titre d'exemple: Millner 1955; Arce 2002; Pohl 2002, 70-79; Strzelczyk 2003.

7 Sur ce peuple (liste non exhaustive): Diesner 1966; Cameron 2000; Pohl 2000 et 2002; Todd 2000; Francovich Onesti 2002; Berndt 2007; Castritius 2007; Merrills - Miles 2010, 5-7; Modéran 2014; Lançon 2015; Vössing 2015. Autre approche dans Pohl 2002, 85. Sur une autre source, Possidius de Calama, voir Beltrán Torreira 1988.

$8 \quad$ Le Bohec 2007b. 
Histoire de la persécution vandale en Afrique, les a peints comme des ennemis cruels; Procope, venu de l'Orient grec, avait accompagné l'armée byzantine qui a repris l'Afrique aux Vandales, dont il laisse une image un peu moins sinistre. Les autres écrivains appartenaient au milieu ecclésiastique nicéen et africain, ennemi des Vandales ariens et germains. Seul Jordanès aurait pu les peindre sous un jour favorable mais ce Goth, lui non plus, n'aimait pas les Vandales. ${ }^{9}$

Cette documentation a suscité une bibliographie finalement très passionnée et fondée sur une critique des textes qui n'a pas toujours été très heureuse.

Ce sont Merrills et Miles qui ont le mieux renouvelé la problématique en revenant sur la conception que les modernes ont élaborée de ce peuple, en faisant de l'historiographie. ${ }^{10}$ Après avoir identifié une phase romantique, ${ }^{11}$ ils ont distingué un épisode où ces barbares sont présentés comme des destructeurs puis un retour au problème fondamental, leur germanité. De fait, les modernes s'intéressent davantage à deux domaines distincts, la religion et la langue. Il n'en reste pas moins que, si beaucoup de travaux traitent des Vandales en général, un nombre non négligeable s'attache à leur passage en Afrique.

En ce qui concerne l'A frique vandale, l'ouvrage fondateur est dû à Émile-Felix Gautier ${ }^{12}$ et il a ouvert la voie à Christian Courtois; ${ }^{13}$ c'est une école qui fait encore autorité et qu'Henri-Irénée Marrou a qualifiée de scientiste, sans trop s'engager sur la solidité de ce scientisme. ${ }^{14}$ De toute façon, Christian Courtois a eu le mérite de sortir de l'ombre une "Afrique oubliée", la zone située aux marges de l'Afrique utile. ${ }^{15}$ Ses tenants défendent la cause de Vandales qui auraient été accusés à tort de vandalisme. Quelques études ultérieures ont essayé d'apporter des nuances à des jugements entiers. ${ }^{16}$ Des travaux plus récents s'efforcent de prendre position de manière pas toujours convaincante: les jeunes chercheurs surtout, mais pas eux seuls, redoutent qu'on leur reproche de ne pas avoir connu la thèse de Christian Courtois. ${ }^{17}$

\section{La traversée du détroit (429)}

En 429, les Vandales traversèrent le détroit de Gibraltar et débarquèrent en Afrique. ${ }^{18}$ Ce passage pose les premiers problèmes militaires auxquels l'historien est confronté. Pourquoi ont-ils fait ce voyage? Quand et où? Dans quelles conditions? Et surtout: qu'a fait l'armée romaine pour leur barrer la route?

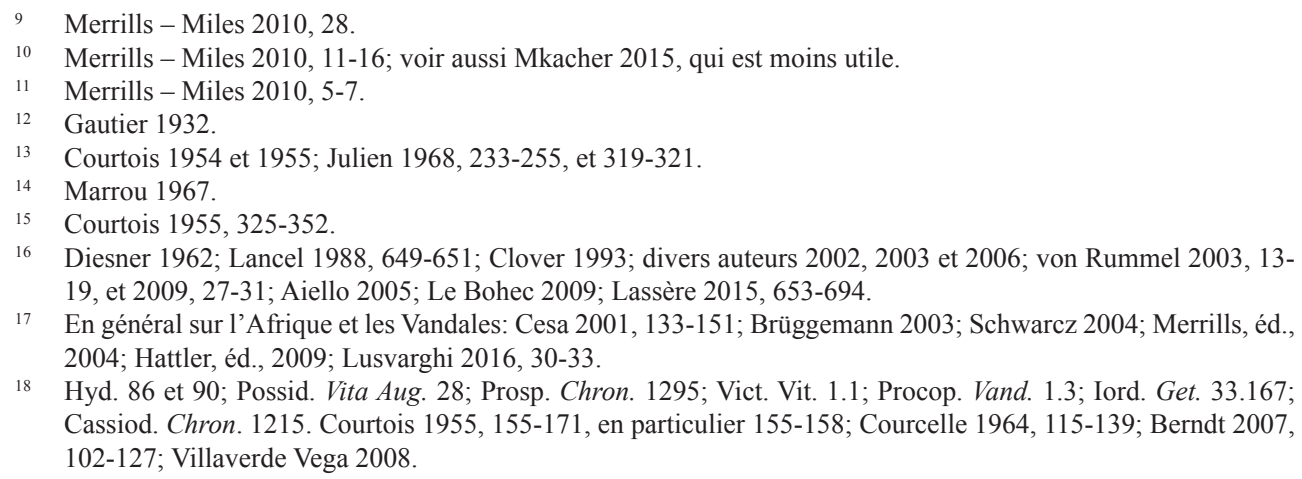

18 Hyd. 86 et 90; Possid. Vita Aug. 28; Prosp. Chron. 1295; Vict. Vit. 1.1; Procop. Vand. 1.3; Iord. Get. 33.167; Cassiod. Chron. 1215. Courtois 1955, 155-171, en particulier 155-158; Courcelle 1964, 115-139; Berndt 2007, 102-127; Villaverde Vega 2008. 
Sans doute faut-il mettre en garde contre l'utilisation d'un vocabulaire anachronique: il vaut mieux éviter de parler d'"émigration", d' "immigration", ou même, plus brièvement, de "migration"; le mot même d" "invasion", pourtant très souvent employé dans le passé, a suscité des réserves. Nous préférons utiliser un terme emprunté au vocabulaire militaire et donc neutre en l'occurrence, "conquête". 19

Cette conquête donc doit être analysée: pourquoi les Vandales se sont-ils emparés de l'Afrique? Sans doute, ici aussi, vaut-il mieux éviter de chercher une explication unique là où au moins deux motifs ont dû jouer. En effet, on verra dans ce dossier la stratégie qu'on appelle d'une expression anglaise, le "pull and push" ${ }^{20}$ D'une part, les Vandales furent chassés de la péninsule Ibérique par les Goths. ${ }^{21}$ Ces deux peuples s'entendaient parfois quand il fallait en piller un troisième, le plus souvent des Romains. ${ }^{22}$ Mais ils se haïssaient le reste du temps ${ }^{23}$ et un conflit ne tarda pas à éclater dans la péninsule Ibérique quand les Goths voulurent s'y installer. ${ }^{24}$ D'autre part, les Vandales étaient attirés par l'Afrique, pour deux raisons. Non seulement c'était le pays où coulaient "le lait et le miel", ${ }^{25}$ mais encore il était mal défendu, point qui sera justifié plus loin. ${ }^{26}$

Le déplacement avait été préparé avec soin, par des raids que Noé Villaverde Vega place entre 426 et 429; il suppose même une occupation de sites de l'un et l'autre côté du détroit. ${ }^{27}$

Cette affaire aurait été simple si des auteurs divers ne l'avaient compliquée en ajoutant une autre problématique; elle a été suscitée par la position prise par Boniface qui, en tant que comte d'Afrique, commandait l'armée qui se trouvait dans cette province. ${ }^{28}$ On sait que l'impératrice Placidie avait provoqué un conflit entre ce personnage et son chef d'état-major, Aetius. Les auteurs anciens et plus encore les modernes sont partagés sur ce qu'aurait fait Boniface dans cette situation. ${ }^{29}$ Pour les uns, il aurait appelé les Vandales pour le soutenir contre ses ennemis; il était donc un traître..$^{30}$ Pour d'autres, ce bon chrétien ne pouvait pas être un traître, et donc cette demande a été inventée par ses ennemis..$^{31}$ Pour d'autres encore, il aurait peut-être demandé du secours aux Vandales, mais ce n'est pas sûr d'après eux, et de toute façon, s'il l'a fait, il l'a regretté aussitôt..$^{32} \mathrm{Au}$ total, il a été soit un traître, soit un imbécile, soit les deux à la fois. ${ }^{33}$

\footnotetext{
Lors du colloque La pérdida de las Hispanias, un collègue a fait remarquer que le terme "conquête" avait une signification péjorative dans le monde ibérique. Il est employé ici dans un sens purement militaire.

20 Modéran 2014, 98.

Cassiod. Chron. 1215.

Iord. Get. 244 et 299.

Iord. Get. 173 et 184 .

Hyd. 60 (a. 416); Iord. Get. 163 et 166.

Modéran 2014, 95.

Gil Egea 1998, 186-189 et 195-215; Merrills - Miles 2010, 52.

Villaverde Vega 2001, 200, n. 833, et 348.

Courtois 1955, 234 et 236; Pohl 2002, 78; Wijnendaele 2015; Lusvarghi 2016, 33-34.

Hyd. 77 (a. 422); Procop. Vand. 1.3. 3-5; Iord. Get. 167; Greg.Tur. Hist. Franc 2.2. Romanelli 1959, 646-648; Hattler, éd., 2009, 174-175 et 178.

30 Neri 2008, 959-975; Merrills - Miles 2010, 53-54.

31 Courcelle 1964, 117; Cesa 2001 (Rubbettino), 133-151; Modéran 2014, 98.

32 Lancel 1999, 658-662.

33 Le Bohec 2005, 255, n. 4.
} 


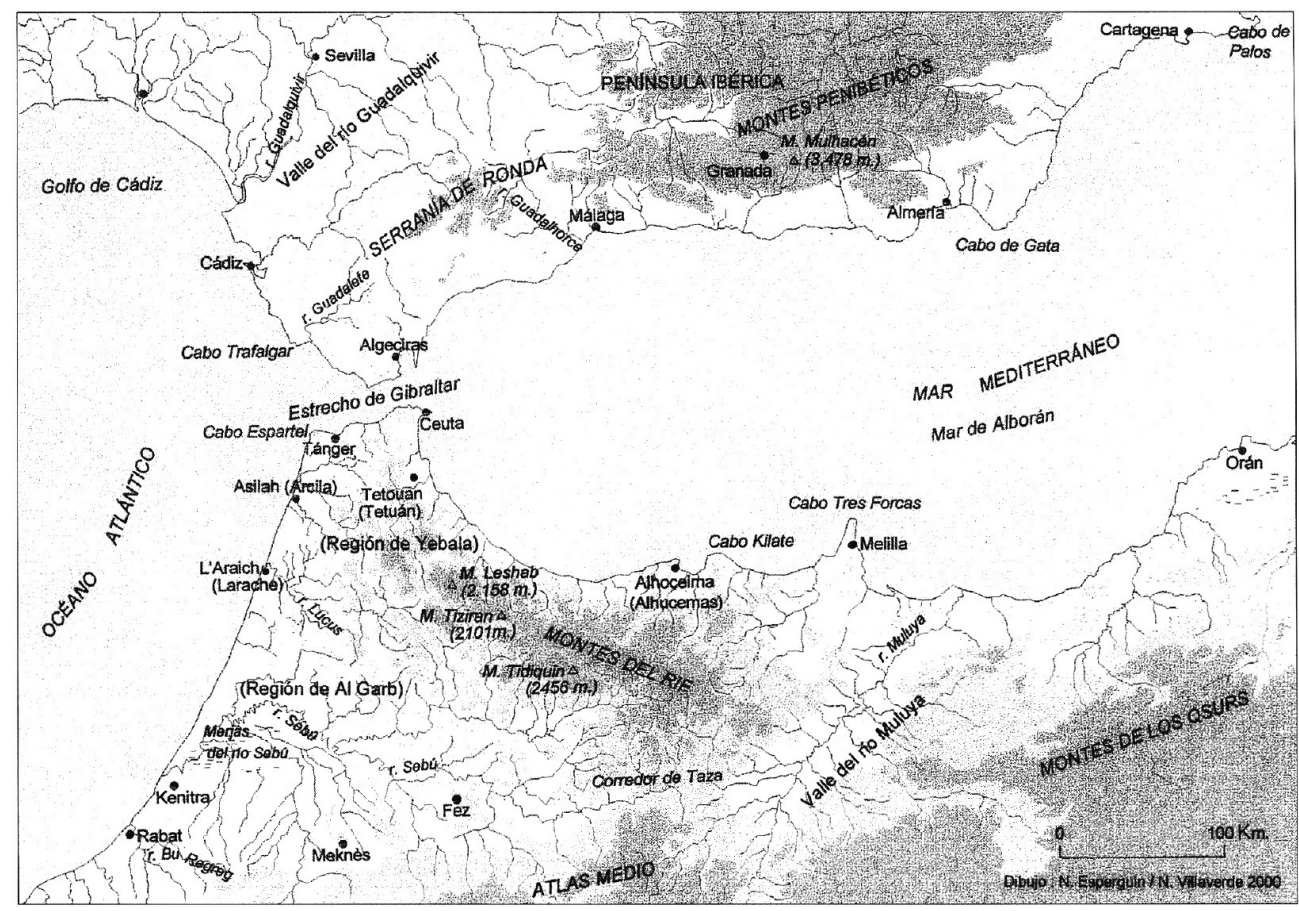

Figure 1. Le détroit de Gibraltar (Villaverde Vega 2001, 39). Différentes possibilités qui s'offraient aux Vandales pour traverser la mer.

L'habitude s'est prise de parler "des Vandales". En réalité, plusieurs peuples étaient plus ou moins bien représentés dans cette masse: Vandales et Alains pour Victor de Vita, Vandales, Alains et Goths pour Bède, Vandales, Alains, Goths et d'autres peuples non nommés pour Possidius de Calama. ${ }^{34}$ Mais personne ne doute que les Vandales aient été l'élément numériquement dominant.

Quoi qu'il en soit, les Vandales sont arrivés en Afrique, et cet événement peut être daté du mois de mai 429.35

Si la date ne prête pas à discussion, il n'en va pas de même avec le lieu (Fig. 1). Certes, ce fut le détroit de Gibraltar, mais où précisément? Trois auteurs anciens donnent des chiffres de distance différents pour ce trajet: 10,3 kilomètres ( 7 milles romains) d'après Jordanès, ${ }^{36} 14,2$ kilomètres ( 80 stades, s'il s'agit bien de stades attiques) selon Procope,$^{37}$ et 17,6 kilomètres (12 milles romains) chez Victor de Vita recopié par Grégoire de Tours. ${ }^{38}$ Or l'écart le plus court entre l'Europe et l'Afrique, dans ce secteur, est de 14,4 kilomètres; mais ce parcours n'était jamais emprunté, parce qu'il aboutissait à une zone montagneuse et à une côte inhospitalière. Il en découle deux conclusions: ces auteurs donnaient la distance entre les deux continents et pas les trajets réels, et c'est Procope qui était le plus précis.

34 Vict. Vit. 2.39; Beda, 480, dans Chron. Min. 3; Possid. Vita Aug. 28. Berndt 2007, 146-169.

35 Chron. Gall. a. CCCCLII, 107-108. Romanelli 1959, 646-648; Lancel 1999, 663; Francovich Onesti $2002,36$.

36 Iord. Get. 167.

37 Procop. Vand. 1.1.2.

38 Vict. Vit. 1.1; Greg.Tur. Hist. Franc 2.2. 
En ce qui concerne le trajet, quatre possibilités peuvent être envisagées. Il s'agit, par ordre de préférence pour l'époque vandale, d'Algeciras (Traducta: la localisation de Iulia Traducta a été établie ${ }^{39}$ à un port inconnu, d'Algeciras à Tanger (Tingi), villes qui sont séparées par 37,8 kilomètres, ${ }^{40} \mathrm{~d}$ 'Algeciras à Ceuta (Septem), trajet qui fait la même distance, ${ }^{41}$ et de Tarifa à Tanger, soit 41,2 kilomètres, ce dernier étant le moins probable. L'hypothèse d'un débarquement vers Oran est invraisemblable, mais elle a néanmoins été formulée. ${ }^{42}$

Même si le trajet était bref, il nécessitait le recours à un nombre important de navires, puisque les voyageurs étaient environ 80 000. Christian Courtois avait émis une hypothèse étonnante: les Vandales auraient pris 500 navires de petite taille, capables de transporter cinq personnes chacun; à raison d'un aller et retour par jour, le transfert aurait donc pris un peu plus d'un mois, plus précisément trente-deux jours. ${ }^{43}$ Il est plus vraisemblable que de gros navires ont été réquisitionnés pour une traversée en masse, ${ }^{44}$ qui aurait facilité un débarquement au cas où les Romains auraient voulu intervenir à ce moment propice.

Une marine de guerre aurait pu attaquer cette flotte en haute mer. Or les Romains n'ont absolument pas réagi, et c'est pour le moins étonnant quand on y réfléchit, effort intellectuel qui a rarement été fait, il est vrai. Tout d'abord, remarquons qu'ils avaient été prévenus. Des raids avaient précédé ce transfert de populations; quelques expéditions de pillage avaient visé plusieurs sites, Ceuta, Zilil, Alquazarseguer et Tanger, sans susciter de réaction importante et surtout sans inquiéter les autorités romaines. ${ }^{45}$ Non seulement ces dernières n'ont pas pris de mesures contre les Vandales pendant la traversée, mais encore elles n'ont pas empêché le débarquement, épisode tactique qui pourtant correspond toujours à un moment difficile. Le fait est avéré depuis César voulant envahir la Bretagne en 55 et 54 avant J.-C. jusqu'au 6 juin 1944. Des soldats en mer puis sur une plage sont exposés à des coups mortels; même Victor de Vita, pourtant un clerc, l'avait relevé (I, 1). Il est peu probable qu'il faille incriminer le renseignement: 80000 personnes peuvent difficilement passer inaperçues. Quoi qu'il en soit, l'échec tactique est patent.

L'armée romaine de Maurétanie Tingitane a été complètement absente du paysage militaire. Et pourtant, elle existait, au moins sur le papier; la Notitia Dignitatum 1'a décrite. ${ }^{46}$ Le commandement revenait au magister equitum per Gallias, le général commandant la cavalerie en Gaule. C'était toutefois un signe inquiétant, quand on sait la totale inefficacité de cette armée dans les années 406-409. Il avait sous ses ordres le vicaire d'Hispanie, ce qui n'était guère plus réconfortant, puisque l'armée de ce diocèse avait manifesté une incapacité totale contre les Vandales et leurs alliés entre 409 et 429 . Au troisième niveau, inférieur au général de cavalerie et au vicaire, se trouvait le comte de Tingitane, qui ne devait pas tarder à se montrer aussi mauvais que ses supérieurs. Il disposait pourtant d'une armée territoriale ou d'active totali-

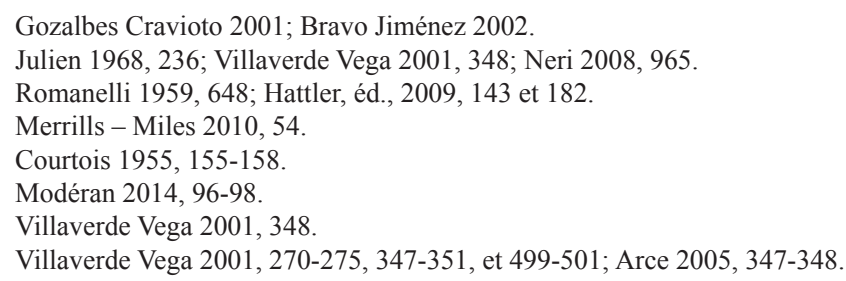


sant 15 unités, soit environ 7500 soldats: 2 légions, 2 unités equitatae, 2 auxilia palatina, 1 aile et 7 cohortes.

Victor de Vita leur attribue un camp important à Septem. ${ }^{47}$ Les archéologues n'ont retenu que quatre enceintes, El-Benian, Tamuda, Suiar el-Habla II et Tabernae. En outre, quatre autres sites militaires sont à leurs yeux des forteresses dont l'existence est seulement possible, Banasa, Sala, Alcazarquivir et un emplacement anonyme aux environs de al-Ma al-Bared. ${ }^{48}$

Il est vrai que 7500 soldats face aux peut-être 20000 barbares, c'était insuffisant. Sans doute aurait-il fallu d'abord empêcher le débarquement et ensuite, en cas d'échec, faire appel aux forces de la province voisine de Maurétanie Césarienne et même de toute l'Afrique. Mais à en croire s. Augustin, témoin direct des événements, le comte d'Afrique, Boniface, était tout à ses affaires personnelles et il ne s'occupait pas de celles qui relevaient du domaine de l'État; et pourtant, dit le saint évêque d'Hippone, il disposait de nombreux soldats. ${ }^{49}$ Ainsi est justifié le jugement qui a été porté plus haut: sa sottise en a fait un traitre.

De toute façon, la résolution du problème militaire en Afrique était rendue plus difficile par l'irruption de deux problèmes religieux. Il est curieux de constater que les historiens du fait militaire, et tous leurs collègues au demeurant, se sont rarement demandés dans quelle mesure la religion chrétienne avait favorisé ou non la résistance par les armes à l'envahisseur. En effet, le commandement "Tu ne tueras pas" demande à être interprété: dans quels cas doit-il être oublié? Dans l'Afrique de 429, deux questions ont été posées à s. Augustin. La première, au cours d'un échange avec Darius, semble futile. S. Augustin assure qu'il vaut mieux faire la paix que la guerre et Darius lui répond que, s'il approuve ce point de vue, il constate qu'il est difficile d'arrêter un conflit avec des paroles. Le deuxième débat porte sur un sujet moins consensuel, et les réactions résultent d'un échange du saint évêque cette fois avec Possidius de Calama: que doit faire le clergé pendant une guerre? Et les réponses que nous avons trouvées sont curieuses. Premier étonnement, les clercs possèdent des armes, du moins si l'on en croit Victor de Vita. ${ }^{50}$ Mais, s'ils en ont, ils ne doivent pas en faire usage. Il ne convient pas aux évêques de fuir, dit Possidius. ${ }^{51} \mathrm{Et}$ les clercs ne doivent pas abandonner les fidèles dans la persécution, conseille le saint. ${ }^{52}$ Donc, si le peuple fuit, il leur est fait obligation de le suivre.$^{53}$ Toutes réflexions faites, quand le problème de fuir ou de rester se pose, il vaut mieux tirer au sort, dit s. Augustin, ce qui ne paraît guère de haute théologie. ${ }^{54}$

\section{Les forces en présence 1: l'armée vandale}

Les Vandales sont arrivés, accompagnés par des Alains, quelques Goths et des représentants de diverses autres ethnies. Leur armée a été peu étudiée, c'est le moins qu'on

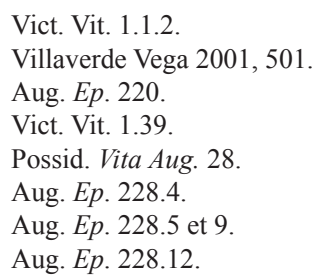


puisse en dire: deux pages bâclées dans un livre de Christian Courtois et un article en polonais. ${ }^{55}$ Pourtant, la question qui se pose est simple mais essentielle si l'on veut comprendre la suite: que valait l'armée des Vandales? Quelle était son efficacité?

\subsection{L'efficacité}

Les débats ouverts à ce propos opposent ceux qui croient en l'efficacité de l'armée des Vandales et ceux qui n'y croient pas, deux thèses qui ont été rarement étayées. De toute façon, la valeur d'une armée est par définition relative: elle se mesure par rapport à son ennemi du jour. Il n'en reste pas moins que des arguments ont été alignés des deux côtés.

À charge, le procureur a été Orose qui a bien connu ces barbares pour avoir vécu dans la péninsule Ibérique (d'ailleurs, il aurait été originaire de cette région pour beaucoup d'historiens). Il décrit "un peuple lâche, cupide, perfide et fourbe", inbellis, avara, perfida et dolosa gens. ${ }^{56}$ Et le même point de vue se retrouve chez Salvien de Marseille qui, par ailleurs, les a décrits comme des barbares chastes, c'est-à-dire d'après nous qu'ils violaient un peu moins que les autres. ${ }^{57}$ Un mot mérite de retenir l'attention dans la critique d'Orose contre les Vandales, l'adjectif dolosus, - $a$. Il fait écho à une entreprise qui viendra plus loin, la prise de Carthage; elle fut obtenue dolo, "par la ruse". Or la ruse, c'est le stratagème, et les anciens étaient partagés à son propos. ${ }^{58}$ Déjà dans l'Iliade, on trouve cette division: Achille était le guerrier courageux, qui combattait l'ennemi face à face, sans tricherie. À l'opposé, Ulysse, "l'homme aux mille tours", était celui qui gagnait grâce à une invention, par exemple le cheval de Troie. Leur tradition rangeait les Romains dans le camp d'Achille; la nécessité les mit dans le clan d'Ulysse. Pour venir à bout d'Hannibal qui inventait ruse sur ruse, il leur fallut recourir aux stratagèmes. Et, même si l'un d'eux, et non des moindres, Frontin, avait compilé un traité des Stratagèmes trois siècles avant s. Augustin, ils ne furent jamais à leur aise avec cette pratique. Mise en œuvre par un ennemi, elle prouvait sa fourberie; inventée par un des leurs, elle montrait son intelligence.

De plus, pour certains de nos contemporains, ils ne formaient pas un grand peuple, car ils étaient trop peu nombreux et militairement faibles. ${ }^{59}$

Un autre reproche se trouve dans des écrits postérieurs. Corippe a écrit qu'ils étaient moins dangereux que les Maures, dont Sidoine Apollinaire a dit qu'ils étaient lâches. ${ }^{60}$ Mais c'est là un lieu-commune contestable. Des Maures servaient depuis longtemps dans l'armée romaine, et ils n'auraient pas été recrutés s'ils n'avaient pas rendu de grands services. Comme on le voit sur la colonne Trajane, les Romains ont utilisé avec profit leurs charges de cavalerie, emmenées par Lusius Quietus; et ils ont occupé une grande place dans les armées qui ont combattu pendant la crise du IIIe siècle.

L'avocat de la défense prétendra qu'au contraire ils formaient un grand peuple, comme le dit Procope qui les met sur le même rang que les Goths, ${ }^{61}$ ce qui est peut-

\footnotetext{
55 Courtois 1955, 230-232; Wilczynski 1993 (nous remercions Mme D. Okon qui nous a procuré une copie de ce texte).

56 Oros. Hist. 7.38.1.

57 Le Bohec 2007, 159, n. 30-31.

58 Wheeler 1988; Brizzi 1989; Le Bohec 2014, 207-208.

59 Merrills - Miles 2010, 29.

60 Coripp. Ioh. 178-185; Sidon. Carm. 5.395-397. Laporte 2005; Modéran œuvres complètes.

61 Procop. Vand. 1.2.1.
} 
être excessif. Il ajoutera qu'ils se sont imposés dans l'empire, sans que personne ne puisse les en chasser, et qu'ils ont vaincu les Romains, au moins à cinq reprises. Ils ont traversé le Rhin, ils ont ravagé une partie de la Gaule, puis de la péninsule Ibérique (où ils ont remporté la victoire sur Castinus en 422), ${ }^{62}$ ils ont franchi la Méditerranée et enfin ils ont conquis l'Afrique.

Leur efficacité s'explique par le fait qu'ils étaient bien armés et bien entraînés, ${ }^{63}$ et aussi par leur férocité. ${ }^{64}$ En outre, étant pauvres, ils n'avaient rien à perdre et ils avaient tout à gagner. Ces facteurs psychologiques sont très important dans une guerre - on le comprend aisément, encore ne faut-il pas les oublier. Mais c'est là que réside tout le problème de la sauvagerie des Vandales: étaient-ils cruels ou non? En lien avec ce tempérament, étaient-ils ou non cultivés? Des réponses à ces questions seront proposées plus loin.

\subsection{Les effectifs}

L'efficacité d'une armée dépendait en partie du nombre de guerriers qu'il était possible d'aligner. Des auteurs anciens, Possidius de Calama et s. Jérôme, ce dernier peut-être inspiré par son prédécesseur, ont invoqué les grandes masses de ces barbares pour expliquer leur succès. Mais c'est leur férocité qui les a fait voir ainsi. En réalité, ils n'étaient pas bien nombreux et tous les modernes acceptent le chiffre donné par Victor de Vita: en tenant compte de tous les humains qui ont traversé la Méditerranée, y compris les vieillards, les femmes, les enfants et les esclaves, on arrive au chiffre de 80000 personnes ${ }^{65}$ Les modernes en ont déduit que les combattants devaient être entre 15 et $20000,{ }^{66}$ plutôt 15000 que 20000 d'ailleurs.$^{67}$ Nous pensons que ces chiffres sont sous-évalués. En effet, dans les sociétés antiques, les femmes mouraient davantage que les hommes, en particulier pendant la grossesse, lors de l'accouchement et après la naissance du bébé. Les enfants eux aussi étaient décimés par les maladies dites infantiles, qui sont très bien soignées à l'heure actuelle, et qui faisaient alors des ravages. Enfin, les vieillards étaient également moins présents que de nos jours: l'espérance de vie se situait entre 45 et 50 ans. Cette société était donc très masculine, comme toute société antique, et il nous semble qu'il faut estimer que les guerriers étaient plus de 20000 . Ces chiffres montrent en outre que les Vandales n'ont pas utilisé tout de suite les auxiliaires africains dont ils ont ensuite bénéficié. Malgré tout, 80000 personnes, c'est un chiffre élevé qui explique aussi la lenteur de la progression de cette masse. ${ }^{68}$

\subsection{L'encadrement}

L'efficacité d'une armée dépendait aussi en partie du type d'encadrement auquel elle était soumise. Mais ici, les précisions font défaut. Le roi, Geiserich, jadis appelé

\footnotetext{
62 Hyd. 77.

63 Possid. Vita Aug. 28.

64 Hyd. 48; Hieron. Ep. 113.15.2-4. Là-dessus, voir l'œuvre de Victor de Vita en entier.

65 Vict. Vit. 1.2. Romanelli 1959, 649; Lancel 1999, 663; Pohl 2002, 76; Merrills - Miles 2010, 54; Modéran 2014, 96 (qui assure que ces chiffres sont fiables); Lusvarghi 2016, 35.

66 Courtois 1955, 230; Francovich Onesti 2002, 29; Pohl 2002, 76; Pohl dans Merrills, éd., 2004, 38.

67 Julien 1968, 236; Kuhoff 2012, 553.

68 Lancel 1999, 663.
} 
Genséric par les historiens, commandait en chef. ${ }^{69}$ Il avait reçu autorité sur les Vandales en 427 avec le titre latinisé de rex Vandalorum; son pouvoir s'est étendu dès 428, puisqu'il est alors devenu roi des Vandales et des Alains. Soumis à un roi, ce peuple n'était donc pas foederatus, "allié" des Romains, a-t-on dit. ${ }^{70}$

Le souverain était accompagné par des comites, mot qui a donné comte en français, et qui désignait des hauts personnages qui le défendaient et le conseillaient au besoin. $^{71}$

Nous trouvons ensuite et en-dessous des millenarii, mot latin qui correspond sans doute au chiliarque grec; Victor de Vita mentionne un millenarius ${ }^{72}$ et Procope parle de 80 chiliarques. ${ }^{73}$ Sans doute faut-il voir là l'existence d'un système décimal. ${ }^{74}$ Ce titre de millenarius correspond sans doute au tribun de l'armée romaine, un officier qui commandait une unité dite "milliaire" ou deux cohortes dites "quingénaires". Mais "milliaire" ne veut pas dire strictement "de 1000 hommes", sinon les 80 chiliarques auraient eu sous leurs ordres une armée de 80000 hommes. Comme chez les Romains, ces chiffres dépassaient de beaucoup les effectifs réels, et les 80 officiers correspondent à une époque où l'armée vandale avait intégré de nombreux auxiliaires africains. Nous n'osons pas imaginer que des centurions se trouvaient encore en-dessous.

Nous sommes encore plus mal renseignés pour le niveau inférieur. L'existence d'une trompette, tuba, suppose la présence d'un musicien pour en jouer. ${ }^{75}$ Un autre texte mentionne un armurier, armifactor, qui était un esclave ${ }^{76}$ et se trouvait donc sans doute en-dehors de l'armée.

Quoi qu'il en soit, la présence du millenarius prouve que l'armée vandale était divisée en unités, sur lesquelles il est difficile de donner beaucoup de précisions. On peut au moins dire qu'elles étaient réparties entre les trois armes, l'infanterie, la cavalerie, et la marine, dans lesquelles servaient les Vandales et les autres envahisseurs d'une part, les alliés africains d'autre part.

\subsection{Les armes}

Paradoxalement, il y a plus à dire sur les cavaliers que sur les fantassins, alors qu'en 429 la reine des batailles était encore l'infanterie, arme qui est surtout connue à travers l'armement qu'elle utilisait; nous y reviendrons au paragraphe suivant.

Dire que l'infanterie jouait le rôle principal sur le champ de bataille, au début du Ve siècle, est une évidence; cette situation caractérisait tous les peuples de l'Antiquité en général et les Germains en particuliers. On sait par ailleurs que les Goths fournissaient une infanterie lourde, puisqu'ils étaient équipés avec une panoplie. Mais chez les Germains, qui combattaient le plus souvent à pied, quelques peuples possédaient des troupes montées qui se révélaient excellentes. Et tel était le cas des Vandales. On cite parfois à ce propos le fait qu'ils avaient fourni 2000 cavaliers à 1'empereur Aurélien (270-275). ${ }^{77}$

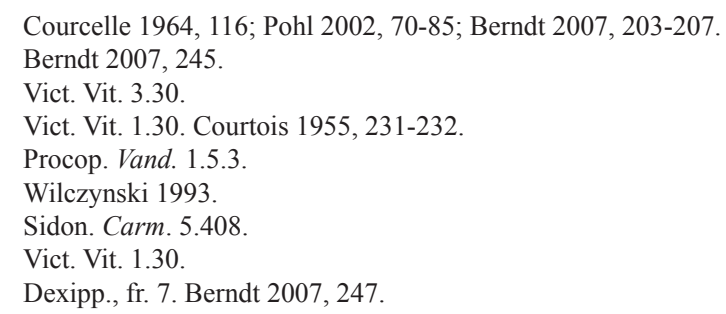


À cet égard, Geiserich pouvait aussi compter sur les Alains. Ce peuple nomade et exotique, venu de l'Ukraine actuelle et parfois surprenant pour les Occidentaux, appartenait au monde des iranophones. ${ }^{78} \mathrm{Au}$ début du Ve siècle, sa cavalerie se divisait encore en deux types de combattants. Les cavaliers légers, qui utilisaient des arcs, des javelots, des lassos et de petits boucliers, semblent avoir joué un moindre rôle à cette époque. Les cavaliers lourds, recrutés dans la noblesse, possédaient casque et cuirasse, épée longue et grande lance. Les Alains possédaient une étrange caractéristique: ils scalpaient leurs ennemis morts. Leur armement est connu notamment par une plaque de ceinturon retrouvée à Orlat, en Ouzbékistan.

Si l'infanterie l'emportait encore par son efficacité en 429, la situation a évolué et, par la suite, la cavalerie a pris de plus en plus de poids dans les batailles. ${ }^{79}$

Quand les barbares venus d'Europe débarquèrent en Afrique et entreprirent de s'emparer de cette terre, ils bénéficièrent d'abord de la neutralité des habitants du pays généralement connus sous le nom de Maures. ${ }^{80}$ Une fois la conquête achevée, les uns et les autres devinrent alliés pour piller l'Italie. ${ }^{81} \mathrm{Il}$ semble que ces Africains aient fourni non seulement des cavaliers mais encore des marins; on sait qu'au temps de la guerre civile entre pompéiens et césariens, les Gétules avaient donné des hommes pour les navires de guerre (il s'agit très probablement de ceux qui vivaient sur les rives de l'actuel golfe de Gabès). De toute façon, et dans toutes les armes, ils devinrent indispensables. Geiserich " $n$ 'accomplit rien par ses propres armes, dit Sidoine Apollinaire. ${ }^{82}$ C'est par les Gétules, les Numides, les Garamantes, les Autololes, l'Arzuge, le Marmaride, le Psylle, le Nasamon, qu'il se fait craindre".

Les Maures devaient rendre d'autres services, notamment dans la marine. Ils ont pu compléter les équipages recrutés par les Vandales et les Alains, dans la péninsule Ibérique d'abord, en Afrique ensuite. Il ne fait aucun doute que des "Romains" ont été plus ou moins contraints de les aider. Il fallait d'abord traverser le détroit de Gibraltar. Pour la suite, si l'on ne croit plus guère à un itinéraire maritime, il n'est pas impossible que des navires aient été utilisés pour la logistique; cette situation créait ce que les militaires appellent une opération combinée. Après la prise de Carthage, Geiserich organisa une grande flotte ${ }^{83}$ et des raids de pillage ont été menés vers la Sicile puis vers l'Italie, jusqu'à Rome.

Les Romains désignèrent ces agresseurs comme des pirates parce qu'ils cherchaient à faire du butin (praeda). ${ }^{84}$ Sur ces navires, si l'on en croit Sidoine Apollinaire, des Vandales étaient embarqués comme rameurs et des Maures comme combattants, ${ }^{85}$ ce qui suppose l'existence de gros bateaux, plus faits pour le transport que pour la bataille navale. Cette division du travail est peut-être un peu schématique: depuis longtemps, les Africains savaient naviguer.

D'après Procope, cette marine serait devenue redoutable avec le temps, notamment à l'époque de Bélisaire, et $\mathrm{M}$. Wilczynski explique cette performance par une

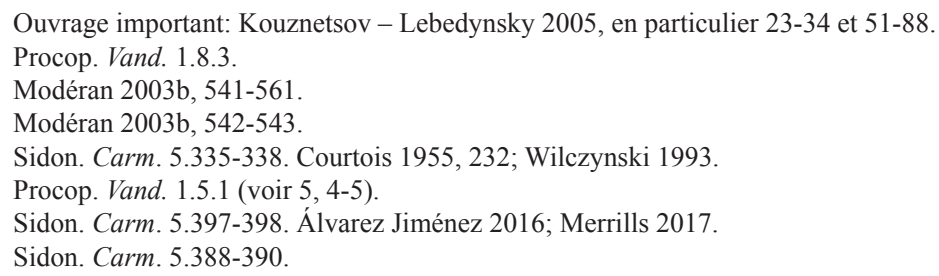


tradition à la fois romaine et punique, ce qui est quelque peu étonnant. ${ }^{86}$ En fait, l'efficacité de la marine vandale s'explique par l'inefficacité de la marine romaine. Ce qui prouve sa médiocrité, c'est que, des décennies plus tard, au temps de la reconquête byzantine, les escadres vandales ne pratiquaient toujours pas la reconnaissance et elles ne possédaient que peu ou pas de navires de guerre proprement dits. ${ }^{87}$

\subsection{L'équipement}

L'armement des Vandales est connu, au moins un peu, à la fois par des textes et par 1'archéologie. Comme armement offensif, ils utilisaient des épées (gladii) ${ }^{88}$ et des armes de jet, des épieux ou des javelots (iacula) ${ }^{89}$ il ne semble pas qu'ils aient possédé des lances de hast et l'archerie a été abandonnée avec le temps; ${ }^{90}$ pourtant au début de leur histoire, ils avaient même su fabriquer des flèches empoisonnées, qui leur permettaient de mener un embryon de guerre chimique. ${ }^{91}$ Dans une tombe datée de la première moitié du IIe siècle, on a trouvé une épée de $98,7 \mathrm{~cm}$, une lance, de fines pointes de javelots et un bouclier à umbo (demi-sphère placée au centre, qui permettait de détourner les armes de jet et de porter des coups à l'adversaire). ${ }^{92}$ Une autre sépulture de la première moitié du Ve siècle renfermait une épée du type spatha (longue et à bout ogival) de $99 \mathrm{~cm} .{ }^{93} \mathrm{Au}$ chapitre de 1'armement défensif, il faut mentionner la cotte de mailles et des femoralia; ce mot désigne des cuissardes, protection du haut de la jambe dans un combat, simple vêtement le reste du temps. Victor de Vita s'indigne parce que ces ariens avaient utilisé des linges d'églises nicéennes pour en fabriquer. ${ }^{94}$

La cavalerie avait fini par prendre une importance extraordinaire chez ces Germains, au point qu'ils ne se déplaçaient jamais sans leurs chevaux, même pour des raids maritimes. ${ }^{95} \mathrm{Il}$ semble bien que tous les cavaliers aient possédé une lance, une épée, et sans doute un arc et une cotte de mailles. ${ }^{96}$ Pour les cavaliers Alains, qu'il ne faut pas négliger, nous renvoyons à ce qui a été dit plus haut.

Les archéologues modernes, quand ils étudient les guerriers antiques, privilégient aujourd'hui ce qu'ils appellent l'équipement, qui regroupe les éléments proprement militaires, l'armement, et les éléments civils, le vêtement. Or, de ce point de vue, les Vandales ont suscité un débat. Victor de Vita, par deux fois, parle d'un habitus barbarus,${ }^{97}$ qui était obligatoire à la cour vandale. ${ }^{98}$ À l'opposé, des archéologues n'ont rien trouvé d'original sur les mosaïques, en particulier sur celle qui montre un chasseur, et dans des sépultures, qui ont livré des "inhumations habillées". 99 Ils ont aussi

\footnotetext{
${ }_{86}$ Procop. Vand. 1.14.1; 1.15.2. Wilczynski 1993; Berndt 2007, 248-249.

87 Álvarez Jiménez 2016; Merrills 2017.

88 Hieron. Ep. 123.15.2-4; Vict. Vit. 1.41; 1.47; 2.12.

89 Vict. Vit. 1.41. Todd 2000, 39-47.

90 Procop. Vand. 1.8.3.

91 Sidon. Carm. 5.398-401; Vict. Vit. 1.41.

92 Hattler, éd., 2009, fig. 107-109.

93 Hattler, éd., 2009, fig. 113.

94 Vict. Vit. 1.39. En général chez les Germains, parfois casque et cuirasse: Todd 2000, 39-47.

95 Sidon. Carm. 5.398 et 423.

96 Procop. Vand. 1.8 .3 (lance et épée). Courtois 1955, 232 (arc et cotte de mailles).

97 Et pas d'un habitus Vandalorum.

98 Vict. Vit. 2.8.

99 Duval 2002; Kleemann dans divers auteurs, 2002, 123-129, 2 fig.; von Rummel 2005, et dans divers auteurs, 2002.
} 
vu des Vandales portant une tunique à manches longues tombant à mi-cuisse, et de hautes bottes remontant au genou. ${ }^{100}$ Ils en ont déduit que les Vandales ne portaient pas de vêtement ethnique et que les personnages connus étaient habillés comme des nobles, pas comme des barbares. Peut-être faut-il nuancer ce propos. Rien n'interdit de penser qu'ils portaient des vêtements barbares et simples à la cour, romains et riches à la maison et dans la tombe.

L'armement n'explique pas toute l'histoire militaire des Vandales. Il faut lui ajouter la poliorcétique, peut-être moins efficace qu'on ne l'a dit.

\subsection{La poliorcétique}

Les modernes sont divisés sur le talent des Vandales lors des sièges.

Au chapitre de leurs mérites, il faut constater qu'ils ont connu des succès. Dans la péninsule Ibérique, ils ont pris villes et ports. ${ }^{101}$ En 419-420, ils ont assiégé les Suèves qui s'étaient réfugiés dans la montagne où ils avaient trouvé l'abri de forts. ${ }^{102}$ Ils savaient construire des camps, art qui n'est attesté que tardivement il est vrai, ${ }^{103}$ et ils avaient mis au point des tactiques très simples: le stratagème, déjà évoqué, et la terreur. Dans ce dernier cas, ils tuaient des civils pour effrayer leurs ennemis et ils laissaient pourrir les corps au pied des murailles avec l'espoir supplémentaire que les assiégés seraient chassés par l'odeur. ${ }^{104} \mathrm{Il}$ faudra revenir sur le thème de la "cruauté" des Vandales.

Ils ont pourtant rencontré bien des difficultés, notamment devant Hippone et Carthage, et quelques auteurs jugent avec sévérité leur poliorcétique. ${ }^{105}$ On rappellera d'abord que s. Augustin est mort le 28 août 430, au troisième mois du siège d'Hippone, ${ }^{106}$ un siège qui fut long et difficile, ${ }^{107}$ et dont l'issue reste incertaine. Il semble que les Vandales ne réussirent pas à faire capituler les habitants ni à prendre d'assaut leur ville. Néanmoins, elle finit par être évacuée et Geiserich en fit au moins provisoirement sa capitale. Dans le cas de Carthage, ${ }^{108}$ ils ne tentèrent même pas le blocus ni l'assaut, mais ils réussirent en recourant à un stratagème, dolo; nous reviendrons sur ce siège.

À défaut d'autres mérites militaires, les Vandales ont su inventer des stratagèmes, ce qui leur a été reproché par les Romains, qui les ont accusés de mensonges et de traîtrises. Ces reproches étaient, si l'on peut dire, de bonne guerre.

Avant de quitter l'armée des Vandales, il faut les priver d'une qualité qui leur a été indûment attribuée. Vincenzo Aiello dit qu'ils ont organisé un "limes" et même, ce qui est assez inédit, un limes maritime. ${ }^{109}$ Nous verrons plus loin qu'ils ont plutôt désorganisé toutes les défenses statiques de l'Afrique, ce qui a facilité la reconquête byzantine.

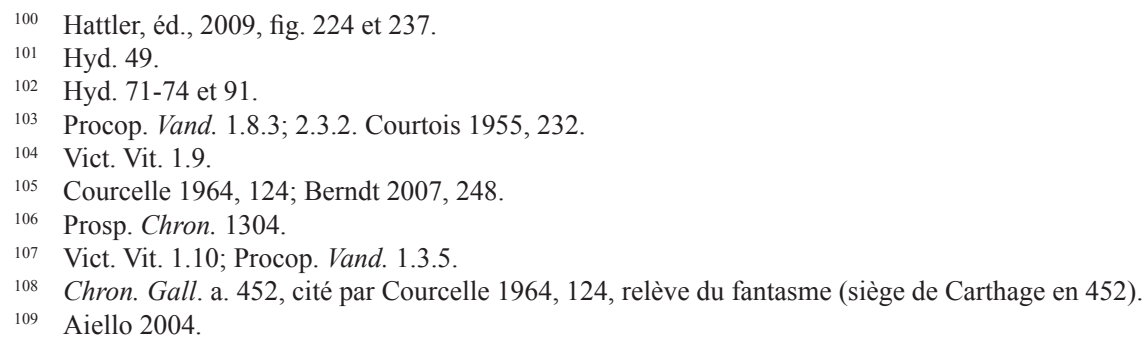




\section{Les forces en présence 2: l'armée romaine}

Pour connaître l'armée romaine d'Afrique au début du Ve siècle, plusieurs types de sources sont disponibles: un texte discuté, la Notitia Dignitatum, et aussi l'épigraphie et l'archéologie. Une étude récente remet en cause plusieurs des affirmations anciennes de René Cagnat (Fig. 2). ${ }^{110} \mathrm{Il}$ est inutile de revenir ici sur l'armée de Maurétanie Tingitane, qui représentait pourtant 7500 hommes environ, puisqu'elle a été traitée plus haut; de plus, militairement, elle appartenait davantage au domaine ibérique qu'au domaine africain.

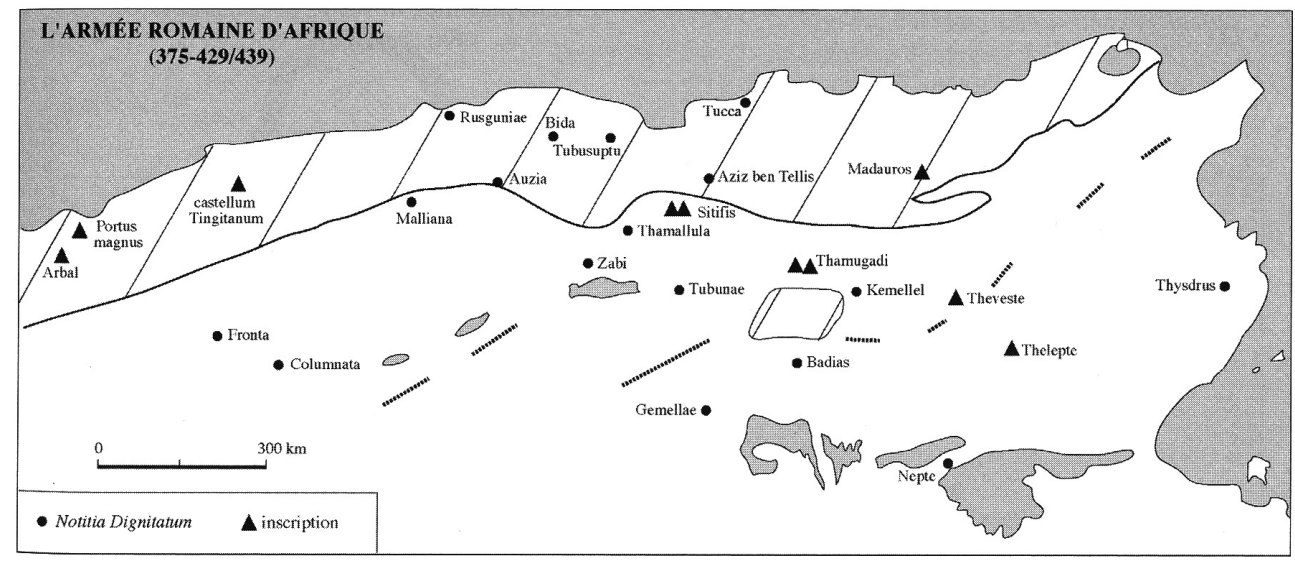

Figure 2. Le dispositif militaire romain en Afrique au moment de la conquête vandale (Le Bohec 2013, fig. 62b, p. XXXVIII). Défense en profondeur telle qu'elle pouvait être conçue au IV ${ }^{\mathfrak{E}}$ siècle, c'est-à-dire qu'elle était formée par un étalement des unités depuis la frontière jusque vers l'arrière.

\subsection{L'efficacité}

Pour ne pas alimenter inutilement la polémique, il nous a paru plus utile de donner à ce paragraphe le titre d'“efficacité"; il eût été néanmoins plus juste de l'intituler "l'inefficacité", ce que démontrera le paragraphe consacré à ses défaites devant les Vandales qui, pourtant, n'étaient pas aussi dangereux qu'on l'a dit.

Yves Modéran, dans son dernier livre, admet cette médiocrité: "L'armée romaine s'avéra totalement incapable d'arrêter (les ennemis)". ${ }^{111}$ Il explique cette situation par l'affaire d'Héraclius, qui connut son épilogue en 413. ${ }^{112}$ En 409-410, ce personnage était comte d'Afrique, donc commandant de l'armée qui se trouvait dans cette région. Mais il se souciait davantage de l'empire que de l'Afrique, et davantage de sa carrière que de ses devoirs: soutien d'Attale, il était entré en conflit avec Honorius. ${ }^{13}$ En prévision d'une éventuelle rencontre armée, il refusa d'intervenir avec des

\footnotetext{
110 Le Bohec 2007a; voir Pohl 2002, 77.

111 Modéran 2014, 96.

112 Modéran 2014, 107-110; voir aussi Modéran 2006. Sur cet épisode, en dernier lieu: Le Bohec 2005, 204-205.

113 Zos. 6.7 (auteur moins mauvais qu'on ne le dit parfois).
} 
soldats en Afrique. ${ }^{114}$ En 413, il fut accusé de complot, et il essaya d'éviter une condamnation en prenant les devants et en provoquant une guerre civile. Il débarqua en Italie, fut vaincu et tué à Otricoli (Utriculum) où son armée fut anéantie. ${ }^{115}$

À notre avis, l'armée romaine d'Afrique était extrêmement médiocre (et encore est-ce une litote), et cela depuis plus longtemps; ${ }^{116}$ elle était inefficace dans son ensemble, quoi qu'en disent les partisans d'un Bas-Empire partout radieux. Un argument se trouve dans l'expédition des Vandales qui, malgré plusieurs points faibles relevés plus haut, l'ont vaincue. Cette inefficacité était plus ancienne que ne le dit Yves Modéran. Au début du règne de Valentinien Ier, Ammien Marcellin était venu en Afrique, et il a laissé un rapport de ce voyage qui est sans appel; il y décrit des unités sans valeur, encadrées par des officiers incompétents; c'était une armée du Bas-Empire. ${ }^{117}$ Le désastre d'Otricoli n'est pas la cause de cette situation, il en est l'illustration. Les Vandales sont entrés dans l'Afrique comme un couteau dans du beurre. Ils n'ont pas rencontré de réelle opposition. ${ }^{118}$

\subsection{La hiérarchie}

La hiérarchie est connue. ${ }^{119} \mathrm{Au}$ sommet, en théorie, c'était l'empereur qui commandait quand il ne s'occupait pas de ses femmes, de ses évêques ou de son poulailler. En fait, le plus souvent il déléguait ses pouvoirs à un général, un barbare dans l'immense majorité des cas. Le général commandant la cavalerie présent à la cour ( $m a-$ gister equitum praesentalis) était placé juste au-dessus du général commandant l'infanterie présent à la cour (magister peditum praesentalis). ${ }^{120}$ Sur le terrain, la principale autorité revenait au comte d'Afrique et aux ducs de Tripolitaine et de Maurétanie Césarienne; en dignité, le comte l'emportait sur les deux ducs. Chacun de ces officiers avait sous ses ordres plusieurs commandants de secteur, dont chacun portait le titre de praepositus limitis.

\subsection{Les effectifs}

L'armée romaine d'Afrique semblait gigantesque à s. Augustin qui s'étonnait de l'inefficacité d' "une armée si grande". ${ }^{121}$ De fait, elle représentait plus du double des effectifs assignés à ces provinces sous le Haut-Empire (à peu près 5000 hommes pour l'Afrique-Numidie et autant pour la Maurétanie Césarienne). L'armée territoriale ou d'active a été estimée par Pietro Romanelli à 21000 soldats ${ }^{122}$ et par Yves Modéran à $23000 .{ }^{123} \mathrm{Si}$ on leur ajoute les troupes qui étaient à la disposition des deux magistri militum, la réserve stratégique dont la fonction était d'intervenir en

\footnotetext{
114 Zos. 6.12.

115 Oros. Hist. 7.41.4-2; Hieron. Ep. 130; Hyd. 51 (voir 56); Zos. 6.9.

116 Le Bohec 2006.

117 Amm.Marc. 27.9.1; 28.6.5.

118 Cette armée était d'ailleurs tout aussi inefficace contre les Africains: Aug. Ep. 220.7.

119 Le Bohec 2007a, 432-433.

120 Sur ces titres: Le Bohec 2015.

121 Aug. Ep. 220.

122 Romanelli 1959, 649-650.

123 Modéran 2014, 107.
} 
Afrique en cas d'agression, on arrive à 30/31 000 soldats, au moins en théorie. Pour établir ce chiffre, il faut comptabiliser les unités.

\subsection{Les unités}

Le magister equitum praesentalis avait sous ses ordres 19 ou 20 unités de cavaliers; ${ }^{124}$ son collègue et subordonné, le magister peditum praesentalis, en commandait 13 (3 légions palatines, 1 unité auxiliaire palatine, 8 légions comitatenses et 1 légion pseudo-comitatensis). ${ }^{125}$

Le comte d'Afrique surveillait 8 ou 9 limites. La Notitia Dignitatum en mentionnait 16, mais son auteur a commis une confusion et il faut en retirer 4 qui relevaient du duc de Tripolitaine et 5 ou 6 qui revenaient au duc de Maurétanie Césarienne. L'épigraphie mentionne plusieurs corps hélas non datés. ${ }^{126}$

Le duc de Tripolitaine disposait de 12 limites, auxquels il faut en ajouter un qui est connu par l'épigraphie et qui a échappé à la Notitia Dignitatum. Dans cette province, on trouve deux centenaria (des fortins), un centenarius (mot mystérieux: centurion?), trois tribuns à Bir ed-Dreder et des constructions à Ghirza. ${ }^{127}$

En Maurétanie Césarienne, le duc commandait les troupes de 11 limites. Des inscriptions, elles aussi non datées, complètent ces informations. ${ }^{128}$

\subsection{La poliorcétique et la stratégie}

La poliorcétique ne nous retiendra pas longtemps. Dans l'Afrique pré-vandale, elle fut surtout défensive. Toutes les villes d'Afrique possédaient des murailles, qui remplissaient plusieurs fonctions. Au premier chef, elles assuraient la protection des habitants, et donc elles avaient un rôle défensif; les Vandales s'en sont aperçus devant Hippone, et c'est ce qui les a décidés à prendre Carthage par la ruse plutôt que par la force. Mais elles permettaient aussi, au besoin, d'imposer le paiement de taxes à ceux qui faisaient entrer ou sortir des marchandises. Et puis elles manifestaient la splendeur de la ville; elles exprimaient l'orgueil des habitants. L'efficacité militaire de ces remparts n'avait pas échappé à Geiserich qui ordonna qu'ils fussent tous rasés. ${ }^{129}$ Seule Carthage échappa à cette mesure, ce qui s'explique sans doute par le fait que cette ville était devenue résidence royale et qu'elle conservait un grand prestige.

Les villes occupaient une place certaine dans la stratégie des Romains. ${ }^{130} \mathrm{Il}$ est vrai que quelques auteurs, jadis, ont écrit que leurs remparts n'avaient pas de fonction militaire, mais servaient uniquement à manifester la richesse des notables; les destructions de Geiserich prouvent au contraire leur rôle éminemment défensif. Il est également vrai que d'autres historiens ont affirmé que les anciens ne pouvaient pas avoir de stratégie. Dans ce dossier, il semble qu'il ne faille pas prendre des

\footnotetext{
124 Le Bohec 2007a, 434.

125 Le Bohec 2007a, 435.

126 Le Bohec 2007a, 436.

127 Le Bohec 2007a, 436-437.

128 Le Bohec 2007a, 437-438.

129 Procop. Vand. 1.5.2.

130 Le Bohec 2014, 238-242.
} 
positions extrêmes. Certes, les Romains ne disposaient pas des instruments qui sont actuellement au service des états-majors; mais ils pouvaient savoir où se trouvait l'ennemi, quels étaient ses effectifs et quel était le chemin à prendre pour l'atteindre. Dans ces conditions, on peut parler non d'une "grande stratégie" mais d'une "petite stratégie". 131

Et cette petite stratégie, qui avait été mise en place sous le Principat, a été complètement tournée. En effet, elle avait été conçue pour barrer la route à un ennemi qui aurait surgi du Sahara, un désert des Tartares, car nul ne vint jamais du sud. Et quand un vrai danger se présenta, ce fut par le nord. Les Vandales ont tourné le système défensif des Romains, en arrivant depuis la péninsule Ibérique.

Sous le Principat, les stratèges romains avaient disposé leurs forts et fortins entre l'Afrique utile et le Sahara. Sous le Bas-Empire, des unités avaient été déplacées vers l'arrière pour deux sortes de raisons. D'une part, ce mouvement répondait à une nouvelle conception défensive, une stratégie en profondeur. D'autre part, il facilitait la logistique, en rapprochant les soldats-consommateurs des civils-producteurs. ${ }^{132}$

\subsection{Les mythes et les faux-problèmes}

L'histoire de cette période est encombrée d'inventions sur lesquelles ce n'est pas ici le lieu de s'étendre; mais il faut les rappeler.

Des auteurs ont jadis imaginé que les Africains étaient devenus dangereux pour l'armée romaine en recourant au chameau de manière extensive; ils l'auraient ainsi affaiblie à l'arrivée des Vandales. Mais il a été montré que cet animal était présent depuis longtemps en Afrique et qu'il n'a pas aidé à des opérations militaires d'envergure. ${ }^{133}$

Par ailleurs, on voit que le tableau des unités brossé plus haut, et la cartographie, permettent de refuser une opposition entre comitatenses et limitanei. Les soldats-paysans n'ont pas existé et ils ne pouvaient donc pas former une armée "immobile", complément inutile d'une armée "mobile". ${ }^{134}$ La vraie distinction oppose une armée territoriale ou d'active à une réserve stratégique, notions qui n'ont jamais été prises en compte.

C'est le rôle des civils qui pose le plus de problèmes. Influencé par l'idéologie marxiste, un auteur allemand a écrit que les Africains ne s'étaient pas opposés aux Vandales parce qu'ils appartenaient à des milieux sociaux hétérogènes et qu'ils étaient indifférents à l'empire. ${ }^{135}$ Un autre auteur, inspiré par une idéologie différente, moralisatrice et sans doute chrétienne celle-ci, a assuré que les Africains étaient peu motivés et qu'ils manquaient d'esprit de résistance; ils pensaient plus à leur plaisirs qu'à la défense de la province. ${ }^{136}$ Mais, outre le fait que ces affirmations ne reposent sur aucun texte, elles sont absurdes: défendre un pays n'est pas le rôle des civils; c'est la tâche des militaires.

\footnotetext{
1 Le Bohec 2014, 277-278.

Le Bohec 2007a, 438.

Le Bohec 2007a, 438, avec la bibliographie antérieure.

Le Bohec 2007a, 438-439.

35 Diesner 1962, 97-111.

136 Courcelle 1964, 128-130.
} 
Toutefois, cette faible résistance pourrait étonner, puisque les prêtres nicéens, dit Victor de Vita, possédaient des armes. ${ }^{137}$ Ils ne s'en sont pas servis, car ils ont vite compris qu'elles seraient inefficaces contre des soldats, surtout des soldats vandales.

\section{La progression des Vandales (429-431)}

Les historiens considèrent que la marche des Vandales en Afrique s'inscrit dans un grand mouvement de peuples qu'ils appellent d'un mot allemand la Völkerwanderung. ${ }^{138}$ Du point de vue de la stratégie, il s'agit d'une expédition ${ }^{139}$ sans retour, une campagne unique avec le flanc droit exposé à l'ennemi; un danger pouvait toujours venir de la mer, à condition bien sûr que l'ennemi possédât une marine et une infanterie quelque peu efficaces.

La chronologie des débuts est appuyée en partie sur la correspondance de s. Augustin: la lettre 220 a été datée de 428 et les lettres 228-231 de novembre/décembre 428 à mars 429 (Fig. 3). ${ }^{140}$

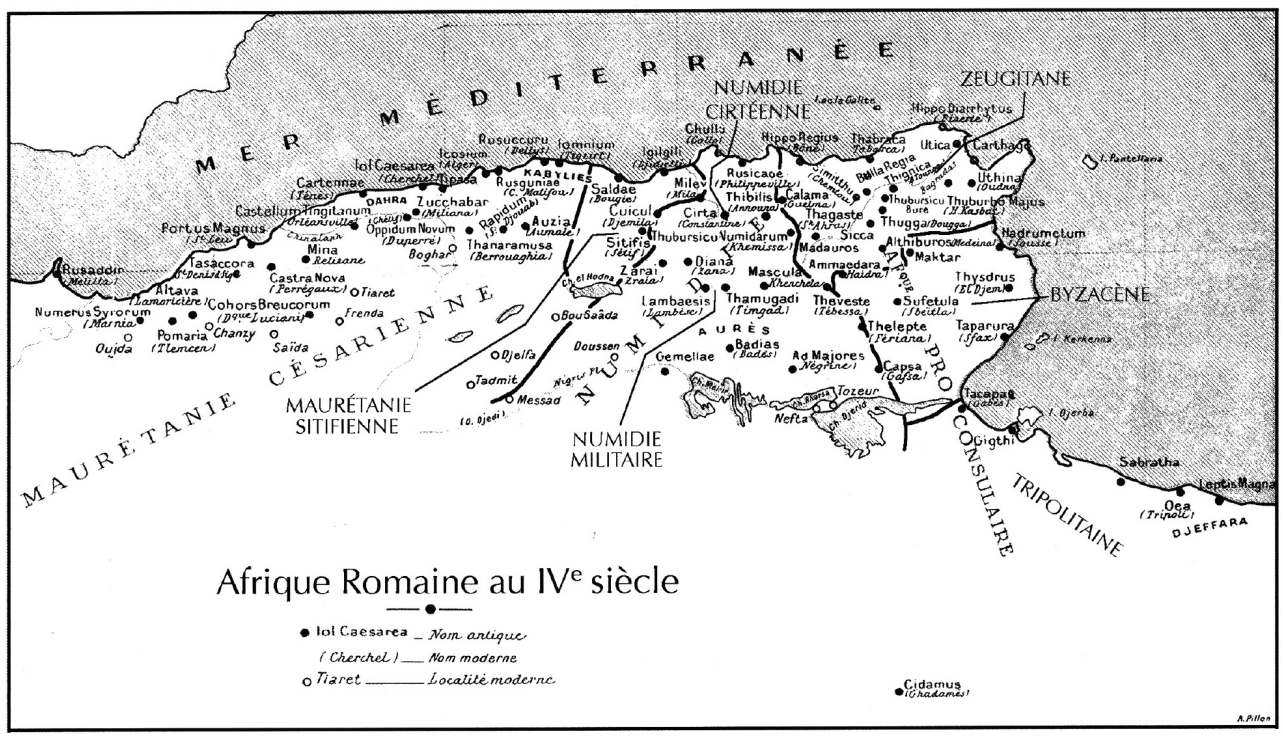

Figure 3. Les cités de l'Afrique romaine (Le Bohec 2013, fig. 61, p. XXXVIII). Après avoir débarqué en Maurétanie Tingitane, les Vandales sont allés vers la partie la plus densément peuplée et la plus riche de l'Afrique antique, le nord-est, la Zeugitane. Ils ont été arrêtés par le siège d'Hippone, puis ils ont marché sur Carthage, ce qui leur a donné les deux plus grandes villes de l'Afrique.

\footnotetext{
137 Vict. Vit. 1.39.

138 Courtois 1955, 155-214; Romanelli 1959, 648-649; Pohl 2000 et 2002; Berndt 2007, 128-129.

139 Sur le sens militaire de ce mot: Expeditio, dans Le Bohec 2007c, 212-218.

140 Diesner 1963,51 et 92.
} 


\subsection{La marche vers l'est}

Deux thèses sont en présence; seule la seconde peut être prise en considération, mais il n'est pas possible d'éliminer la première sans en parler. ${ }^{141}$

En effet, Christian Courtois a envisagé une hypothèse curieuse qui fonde la première thèse: les Vandales auraient emprunté la voie de mer pour longer la côte africaine. ${ }^{142}$ Une expédition de ce genre, qui aurait nécessité le recours à deux ou trois cents gros navires, ${ }^{143}$ à raison de plus de deux cent cinquante personnes par bateau, paraît invraisemblable: déplacer 80000 humains par voie de terre, c'est ce que dit Procope, c'était plus raisonnable, et c'est d'autant plus crédible que les principaux épisodes suivants se sont déroulés sur terre. La critique de cette première thèse n'élimine pas totalement une possibilité: la logistique, et elle seule, aurait été assurée par voie de mer.

L'hypothèse la plus vraisemblable reste donc la deuxième thèse, le voyage par voie de terre. C'est celle que rapporte Procope, un écrivain tardif il est vrai, mais qui avait eu en main des documents sérieux. Il dit en outre que le trajet entre Gibraltar et Tripoli (Oea) peut être parcouru en 90 jours; ${ }^{144}$ la vraie distance est de 2000 kilomètres, en droite ligne et sans obstacles. Il est possible de le décomposer pour suivre les principales étapes des Vandales: le trajet Gibraltar-Hippone fait 1275 kilomètres, soit 50 jours; pour Hippone-Carthage, on aura 225 kilomètres, soit 10 jours. La notation de Procope permet de comprendre les difficultés qu'impose un tel déplacement; sa durée pourra être comparée au temps réel qu'a demandé chaque étape, ce qui sera vu plus loin. Une thèse mixte, qui relève davantage de la poésie que de l'histoire, a été envisagée par Pierre Courcelle: cabotage jusqu'à la Moulouya, voyage par voie de terre ensuite. ${ }^{145}$

J. Le Gall, qui voulait prouver que les Vandales étaient passés par Altava, à l'intérieur des terres, décomposa leur trajet: ${ }^{146}$ de Tanger à Volubilis puis par une voie de l'intérieur jusqu'à Altava (il croyait que la trouée de Taza était occupée à l'époque romaine, ce que personne n'admet plus aujourd'hui, depuis une étude de M. Euzennat); par le littoral jusqu'à Cherchel; de nouveau par l'intérieur d'Auzia à Guelma (Calama). Il devient moins assuré pour la suite, hésitant entre un trajet direct de Guelma vers Hippone, et un trajet indirect, avec un crochet par Carthage, ce qui nous étonnerait.

Le passage par la voie de terre a laissé des traces plus ou moins évidentes. D'après les historiens modernes, deux routes s'offraient aux voyageurs, celle qui longeait le littoral, la plus importante, et celle qui passait par l'intérieur, plus au sud, à une cinquantaine de kilomètres de la première. Une inscription d'Altava, qui a retenu toute l'attention de J. Le Gall et qui est datée (pour une fois) avec précision d'août-septembre 429, mentionne une dame "tuée par le glaive des barbares". ${ }^{147} \mathrm{Il}$ est possible que les meurtriers aient été des Africains, mais la coïncidence chronologique incite à créditer les Vandales de ce décès; c'est la solution qu'a préférée J. Le Gall. ${ }^{148}$ Or Alta-

\footnotetext{
141 Le Gall 1936; Lusvarghi 2016, 35-38.

142 Courtois 1955, 161.

143 Bockius dans Hattler, éd., 2009, 182-183.

144 Procop. Vand. 1.1.4.

145 Courcelle 1964, 117.

146 Le Gall 1936, 272.

$147 A E$ 1935, 85. Modéran 2014, 102.

148 Le Gall 1936, 273.
} 
va se situe à quelque cinquante kilomètres dans les terres. Dans ce cas, il s'agit sans doute d'un raid; la dame ne se trouvait pas sur la route des Vandales. Par ailleurs, un trésor a été trouvé à Tenes, à quelque deux cents kilomètres à l'ouest d'Alger, et il correspond chronologiquement au passage des barbares. ${ }^{149}$ Cette découverte constitue un argument en faveur de la thèse qui privilégie le trajet par voie de terre et le long de la côte.

\subsection{Une bataille en rase campagne}

À la fin du printemps 430, le comte Boniface se décida à arrêter la progression des ennemis. ${ }^{150}$ Il choisit de provoquer une bataille en rase campagne, quelque part à l'ouest d'Hippone; pour cette rencontre, il disposait de combattants Goths. La présence de ces soldats n'est pas sans intérêt. Elle montre que ces troupes, qui ne sont pas attestées dans l'armée d'Afrique, avaient été envoyées par les deux magistri militum, ou par l'un des deux seulement; elles appartenaient à cette sorte de réserve qui était à la disposition du pouvoir central et que les modernes désignent comme les comitatenses. Nous tirons de la présence de ces soldats deux conclusions: d'abord, et contrairement à ce que pensait Y. Modéran, il faut prendre en compte les effectifs des magistri militum si l'on veut comprendre comment était prévue la défense de 1'Afrique; ensuite, et contrairement à ce que disent beaucoup d'auteurs actuels, l'armée romaine du Bas-Empire ne possédait pas une grande valeur. Pourtant, cette intervention de Goths incite à supposer que le succès était prévu, car ces barbares l'ont souvent emporté sur les Vandales. Mais Possidius de Calama et s. Augustin, s'ils les ont jugés nombreux, ont vu qu'ils étaient peu motivés et totalement inefficaces. ${ }^{151} \mathrm{De}$ fait, cette bataille en rase campagne se solda par un échec complet de Boniface, qui apporta ainsi une preuve supplémentaire de son incompétence.

\subsection{Le siège d'Hippone ${ }^{152}$}

Après leur victoire en rase campagne, les Vandales arrivèrent sous les murs d'Hippone et ils voulurent s'emparer de la ville, une des plus grandes et des plus riches de l'Afrique, toujours célèbre de nos jours pour avoir été l'évêché de s. Augustin. Elle était défendue par un solide rempart, qui n'a pas laissé de traces exploitables par les archéologues. ${ }^{153} \mathrm{Il}$ n'existe aucun renseignement précis sur les défenseurs, qui furent sans doute des habitants contraints à devenir soldats de circonstance, renforcés par quelques Goths placés sous le commandement de Boniface. ${ }^{154}$ Le siège dura quatorze mois ${ }^{155}$ et il débuta au début de juin (fin mai pour quelques auteurs). ${ }^{156} \mathrm{Au}$ troisième mois de siège, le saint mourut, à l'âge de soixante-seize ans; c'était le 28 août $430 .{ }^{157}$

\footnotetext{
149 Lancel 1999, 736, n. 24. Citons pour mémoire le très hypothétique siège de Cirta: Courcelle 1964, 124.

150 Procop. Vand. 1.3.5. Modéran 2014, 102.

151 Aug. Ep. 220; Possid. Vita Aug. 28. Merrills - Miles 2010, 54.

152 Possid. Vita Aug. 28; Vict. Vit. 1.3-7. Courtois 1955, 163; Romanelli 1959, 652-653; Lancel 1999, 663-665; Francovich Onesti 2002, 36; Berndt 2007, 130-134; Vössing 2012.

153 Lancel 1999, 732, n. 31.

154 Possid. Vita Aug. 28. Merrills - Miles 2010, 54.

155 Possid. Vita Aug. 28.

156 Lancel 1999, 663.

157 Possid. Vita Aug. 28. Lancel 1999, 665.
} 
Le moins qu'on puisse dire est que les Vandales ne firent pas preuve d'une grande maîtrise de la poliorcétique. Ils essayèrent de prendre la ville d'assaut: ce fut un échec. Ils tentèrent de l'affamer: autre échec. Finalement, eux-mêmes ressentirent la faim et ils levèrent le siège. ${ }^{158}$ Mais, pour des raisons difficiles à comprendre, les habitants quittèrent la ville: "L'issue du siège d'Hippone demeure un mystère". ${ }^{159}$ Les Vandales, revenus après avoir appris cette nouvelle, la pillèrent et la livrèrent aux flammes. ${ }^{160}$ La question a été posée de savoir dans quelle mesure elle a été détruite. M. Pizzica, qui s'est intéressé à cette question, a vu une divergence entre Possidius de Calama, qui dit que la ville a été brûlée après le départ des habitants, et Procope qui ne mentionne pas cet incendie; par ailleurs, l'archéologie indiquerait que la bibliothèque et le quartier chrétien ont existé après cet abandon. C'est pourquoi M. Pizzica pense que Possidius a inventé un drame supplémentaire pour des raisons littéraires. Mais l'évêque de Calama ne cherchait pas à séduire les intellectuels de son temps; il voulait surtout montrer la barbarie des Vandales. En réalité, il n'est pas impossible que le quartier chrétien ait été épargné, parce qu'il se trouvait à l'extérieur du rempart ou pour une autre raison. ${ }^{161}$ Quoi qu'il en soit, Geiserich établit à Hippone sa capitale, mais une capitale provisoire, ${ }^{162}$ car il avait un autre projet.

\subsection{Une deuxième bataille en rase campagne}

De nouveaux effectifs furent envoyés, cette fois par l'empereur de Constantinople; c'est dire à quel point le pouvoir occidental était en déliquescence. Ils étaient commandés par un Alain, Aspar, et partirent sans doute depuis Carthage vers Hippone. ${ }^{163}$ Les Vandales se dirigèrent vers l'est, et la rencontre eut lieu peut-être près de Guelma, à la fin de l'été ou au début de l'automne $431 .{ }^{164}$ Il n'existe pas de renseignements sur le combat, qui se solda par une sanglante défaite pour les troupes dites romaines; elles prirent la fuite. Procope assure que Geiserich en profita pour renforcer ses positions en Afrique. ${ }^{165}$

\section{Les dégâts causés par les Vandales}

\subsection{Le problème}

À ce point du récit, il faut aborder un problème qui semble réglé si l'on se fie aux commentateurs actuels. ${ }^{166}$ Christian Courtois a proposé une méthode d'analyse pour déterminer si les Vandales avaient été cruels ou non. ${ }^{167} \mathrm{Il}$ a tout de suite séduit beaucoup d'historiens, sensibles à l'attrait de la nouveauté; seul Henri-Irénée Marrou a paru manifester quelques réticences, mais elles ont été vite oubliées par les commen-

\footnotetext{
158 Procop. Vand. 1.3.5. Julien 1968, 237.

159 Lancel 1999, 667.

160 Possid. Vita Aug. 28. Courcelle 1964, 125.

161 Pizzica 1982-1983.

162 Lancel 1999, 668; Berndt 2007, 130-134.

163 Romanelli 1959, 653; Lancel 1999, 668.

164 Julien 1968, 237; Modéran 2014, 103.

165 Procop. Vand. 1.4.2.

166 Sur le voisinage entre barbares et Romains: Goffart 1980; Hettinger 2001.

167 Courtois 1954, surtout, et aussi 1955.
} 
tateurs, comme il arrive malheureusement trop souvent. ${ }^{168}$ De nombreux chercheurs, qui ne veulent pas paraître ignorants, ou qui croient que le dernier qui a parlé a raison, la suivent plus ou moins aveuglément; ${ }^{169}$ d'autres, les grands auteurs, décrivent la situation avec hauteur et prudence. ${ }^{170}$ Nous voudrions manquer de prudence et reprendre le dossier.

La thèse de Christian Courtois repose sur trois idées. 1. Les Vandales, ennemis-agresseurs de ce conflit, ne sont connus que par des ennemis-agressés, surtout des Africains. ${ }^{171}$ 2. Les ennemis-agressés chargent toujours leurs ennemis-agresseurs. 3. Dans ces conditions, pour rétablir la vérité, il faut toujours et systématiquement, prendre le contre-pied de ce que disent les ennemis-agressés.

Le point 2 est assurément incontestable: une personne agressée n'aime jamais son agresseur. Le point 1 ne l'est qu'en partie: après la conquête, des intellectuels, notamment, et tous ceux qui ont su se rendre utiles aux vainqueurs, ont fait leur soumission aux rois vandales. C'est ainsi que quelques instituteurs africains ont cru bon de rédiger de mauvais vers, inspirés d'auteurs connus, à leur gloire. Des modernes en ont conclu que les Vandales s'étaient convertis en masse à la romanité, au latin et à la poésie, ce qui est pour le moins surprenant; ${ }^{172}$ ces barbares n'auraient rien changé, ni dans le domaine matériel, ni dans le domaine spirituel. ${ }^{173}$ Des Vandales cultivés et érudits, ce n'est pas peu étonnant, ${ }^{174}$ et il y a mieux, puisqu'on a même parlé de "Vandal Renaissance". ${ }^{175} \mathrm{La}$ conséquence plus ou moins explicite de ce bon goût est que des personnes aussi raffinées ne peuvent pas se livrer à des actes de cruauté. Mais ce n'est pas tout; le point 3 est complètement faux: quand les victimes se plaignent, elles n'ont pas forcément tort. À l'heure actuelle, les autorités judiciaires de beaucoup de pays le savent bien, et elles les écoutent avec attention. En conclusion, nous dirons qu'il est logique que les victimes exagèrent, et qu'il est illogique d'exonérer les agresseurs de tout crime. Certes, les Vandales ont agi "comme tout le monde". ${ }^{176}$ Mais avec une barbarie particulière.

\subsection{Les méfaits}

Dans ces conditions, nous soutiendrons une thèse radicalement opposée et sans nuances: les Vandales ont été plus cruels que les autres. Ils ont pratiqué ce que nous avons appelé "la tétralogie des guerres", le vol, le viol, le meurtre et l'incendie, "comme tout le monde"; mais ils lui ont ajouté d'autres méfaits. ${ }^{177} \mathrm{Et}$, d'une manière générale, ils ont commis beaucoup de dégâts. ${ }^{178}$

168 Marrou 1967.

169 Par exemple Neri 2008, 966; Carucci 2012.

170 Lancel 1988, 654-655; Cesa 2001; González Salinero 2001, 2002 et 2014 (à partir de Quodvultdeus); Modéran 2002 et 2012; Pohl 2002, 80-86.

171 Au premier chef, Possidius de Calama, Quodvultdeus et Victor de Vita.

172 Caliri 2012; Coppolino 2012; Tizzoni 2014.

173 Gelarda 2012; Russo 2012.

174 Chalon et alii 1985.

175 Hays 2004.

176 Bourgeois 1980. Courcelle (1964, 118 et suiv.) admet une certaine cruauté, mais il assure qu'elle a été moindre que les Africains ne l'ont dit.

177 Le Bohec 2007b.

178 Chron. Gall. a. CCCCLII, 107-108; Aug. Ep. 228.5; Possid. Vita Aug. 28.4-5 et 7-9; Capr. Ep. 1; Quodv. Temp. bar. 5.7-13; Vict. Vit. en entier; Ferrand. Vita. Fulg. 20 (sous Thrasamund); Procop. Vand. 1.2.1. Pohl 2004, 38; Le Bohec 2007b. 
Les Vandales ont laissé l'image de barbares cruels qui n'épargnent personne, ni les hommes, ni les femmes, ni les clercs, ni les laïcs. ${ }^{179}$ La part du religieux dans leur comportement, c'est-à-dire de la "persécution", ne doit certes pas être exagérée, car ils se sont conduits en soldats du Ve siècle. Elle ne doit pas non plus être sous-estimée: les guerres de religions ont toujours été les plus cruelles de l'histoire. Et ils se sont donc illustrés par la "tétralogie" dont nous avons parlé plus haut; le détail peut en être donné. Ils se sont battus surtout pour le butin, ce qui était alors banal, pour piller, pour voler. ${ }^{180}$ Ils ont aussi violé, et ils ont même violé des religieuses, des femmes consacrées à Dieu, ${ }^{181}$ bien qu'ils aient été de bons chrétiens, comme le dit Salvien de Marseille. ${ }^{182}$ Il est vrai que leurs victimes étaient des nicéennes; sans doute cette caractéristique atténuait-elle leurs hésitations. Ils ont aussi commis des meurtres, pas nécessairement de manière gratuite: leurs victimes succombaient à des interrogatoires trop poussés, à la torture, quand il fallait leur faire dire où elles avaient caché leur or. ${ }^{183} \mathrm{Ils}$ ont, comme tous les hommes de leur temps, allumé des incendies pour célébrer leurs victoires et affirmer leur domination. Ils ont en outre manifesté une satisfaction particulière quand ils pouvaient faire brûler des églises nicéennes. ${ }^{184}$

Les Vandales ont commis d'autres actes plus odieux. Ils ont condamné à l'exil de nombreuses personnes, des notables qui étaient dépossédés de leurs domaines et des gens plus ou moins modestes qu'ils ont vendus comme esclaves. Le père de Fulgence de Ruspe a été chassé de Carthage et Fulgence lui-même a été exilé en Sardaigne; beaucoup de Carthaginois, surtout des notables et des clercs, ont été expulsés vers la Sicile. ${ }^{185}$ Quelques-uns de ces malheureux ont même gagné l'Orient. L'évêque Théodoret de Cyr donne à ce sujet des indications intéressantes, car il cherche à les aider pour pratiquer la charité chrétienne. Caelestiacus, jadis riche propriétaire de Carthage, a été ruiné et il vit désormais de la charité. ${ }^{186}$ Un autre Africain, l'évêque Cyprien, a été condamné à l'exil et il erre sans savoir où se fixer. ${ }^{187}$ Le sort de Marie est encore plus triste. Elle était née dans une famille très aisée. Les Vandales l'ont réduite en esclavage et ils l'ont vendue avec sa servante. Elle a été achetée par des soldats qui l'ont rendue à la liberté. ${ }^{188}$ L'empereur Zénon, lui aussi, a payé Geiserich pour récupérer des esclaves. ${ }^{189}$ On remarque que le souverain et ses militaires ne sont pas capables de prendre par les armes la défense des leurs.

Les deux principaux buts de ces condamnations sont clairs: récupérer des terres et punir les nicéens. C'est surtout le premier point qui a retenu l'attention. Yves Modéran explique qu'il s'agit de la saisie de domaines fonciers et pas, comme on l'a dit, du détournement de revenus fiscaux; Victor de Vita et Procope le disent bien et sont

\footnotetext{
179 Possid. cité ci-dessus.

180 Possid. Vita Aug. 28; Vict. Vit. 1.4; Procop. Vand. 1.2.1. Liste impressionnante et mal fondée dans Schwarcz 2004; point de vue plus modéré, mais très influencé par Courtois 1954 et 1955: Modéran $2003 \mathrm{a}$.

181 Aug. Ep. 228.5 (d'après l'évêque Honoratus); Possid. Vita Aug. 28; correspondance de Léon le Grand, cité dans Courcelle 1964, 123, n. 6.

182 Salvian. Gub. Dei 2.50; 7.26, 90, 91 et 94. Lambert 2000.

183 Aug. Ep. 228.5 (de l'évêque Honoratus au saint); Possid. Vita Aug. 28; Vict. Vit. 1.3; Procop. Vand. 1.2.1.

184 S. Augustin, Possidius de Calama et Victor de Vita, cités à la n. précéd.

185 Ferrand. Vita. Fulg. 1, 9 et 17.

186 Thdt. Ep.Sirm. 2.30-36.

187 Thdt. Ep.Sirm. 2.52-53.

188 Thdt. Ep.Sirm. 2.70.

189 Malch. 3.
} 
d'accord à ce sujet. ${ }^{190}$ Edouard Perroy avait montré que des changements de propriétaires intervenaient dans le cadre d'une pratique attestée dans le droit germanique, la tiercio, qui était une expropriation pure et simple. ${ }^{191}$ Les nouveaux maîtres du sol ont reçu des lots, appelés les sortes Vandalorum ${ }^{192}$ cette conquête s'est inscrite dans un régime qui n'a rien à voir avec l'hospitalitas. ${ }^{193}$

Comme si les exils et les expropriations ne suffisaient pas, les Vandales leur ont ajouté les persécutions religieuses ${ }^{194}$ Ces ariens détestaient les nicéens mais, malgré les qualités intellectuelles qu'on leur a prêtées, il est peu probable qu'ils aient compris le problème théologique qui les séparait des Africains. Plusieurs mesures ont été prises par les rois barbares. Dans le meilleur des cas, les biens du clergé nicéen étaient transférés au clergé arien. ${ }^{195}$ Sinon, les églises étaient purement et simplement pillées. ${ }^{196}$ Et si ces mesures ne suffisaient pas, le culte était interdit. ${ }^{197}$

Une des conséquences de ces transferts de propriété se voit dans l'évolution de l'économie. Quelques optimistes incorrigibles, adeptes des théories de Christian Courtois, qu'ils veulent appliquer à tous les domaines de l'activité, pensent qu'il n'y a pas eu de déclin. ${ }^{198}$ Le moins qu'on puisse dire est qu'il y a eu des dévastations, que les Vandales ont pratiqué une économie de prédation et qu'ils n'ont pas su préserver les entreprises qui existaient avant leur arrivée; on ne s'improvise pas producteur de lampes ou de vaisselle sigillée. ${ }^{199}$ Louis Maurin avait constaté cette dégradation à Thuburbo Maius.$^{200}$ Ces dommages sont rapportés par s. Augustin; ${ }^{201}$ et pourtant, le saint évêque d'Hippone savait ce qu'étaient le droit de la guerre (belli ius) et ses traditions (consuetudo bellorum), comme le montre tout le premier livre de La cité de Dieu.

En conclusion de ce paragraphe, il nous semble juste d'affirmer que les Vandales ont été plus cruels que les autres barbares. Leur présence a marqué "une rupture" (Claude Lepelley) dans l'histoire de l'Afrique. ${ }^{202}$

\section{La progression des Vandales (430-439)}

Une fois installé à Hippone, Geiserich entreprit d'organiser l'étape suivante. ${ }^{203}$ Une bonne activité "diplomatique" prépara une action militaire en deux temps: une expédition fut suivie par un stratagème et ils aboutirent à la prise de Carthage, événement aux conséquences considérables.

\footnotetext{
190 Modéran 2012; voir aussi Berndt 2007, 208-211.

191 Perroy 1954, 59-64.

192 Pohl 2002, 81; Schwarcz 2004, 55-57; Goffart 2012; Tedesco 2012.

193 Schwarcz 2004, 49-50.

194 Ferrand. Vita. Fulg. 5-6, en général.

195 Ferrand. Vita. Fulg. 1.

196 Possid. Vita Aug. 28. Généralités sur le clergé: Rapp 2000; Gwynn 2012.

197 Possidius de Calama, cité.

198 Leone 2007, 127-165.

199 Le Bohec 2016.

200 Maurin 1967.

201 Aug. Ep. 220; 228.11.

202 Lepelley 2005.

203 Procop. Vand. 1.4.12-14. Ausbüttel 1991; Pohl 2002, 78.
} 


\subsection{La "diplomatie"}

On sait qu'un chef d'État cherche à résoudre les problèmes normalement par la politique. Quand il s'agit des affaires extérieures, ce type d'activité s'appelle la diplomatie, qui vise à établir des relations apaisées. En cas de difficultés insurmontables, il recourt à la guerre. C'est simplement ce qu'a voulu dire Clausewitz quand il a écrit que la guerre c'est la poursuite de la politique (en fait de la diplomatie) par d'autres moyens. Les Vandales avaient élaboré une conception de cette pratique qui leur était propre: ils envoyaient des messagers qui promettaient tout ce qu'on voulait, pour endormir la méfiance de leurs interlocuteurs, et ils faisaient ensuite ce qu'ils voulaient. Salvien de Marseille, qui leur reconnaît beaucoup de qualités, notamment le mérite de la chasteté, vertu fondamentale à ses yeux, leur reproche pourtant leur agressivité et mille autres défauts propres à des conquérants, violence, perfidie et non-respect de la parole donnée. ${ }^{204}$

Donc malgré la guerre, ou peut-être à cause d'elle, des relations diplomatiques furent établies entre l'empereur Théodose II et le roi Geiserich; la question a été étudiée récemment. ${ }^{205}$ Des contacts sont attestés en 416 et 428 . Après l'installation du pouvoir royal à Hippone et la deuxième victoire remportée sur les "Romains", les deux parties conclurent un traité, le 11 février $435{ }^{206}$ L'empereur d'Occident était tenu à l'écart d'un accord qui liait les Vandales et Constantinople. Les vainqueurs recevaient le droit de choisir Hippone comme capitale, droit qu'ils avaient déjà pris sans attendre. Les vaincus leur accordaient un domaine qu'ils possédaient également depuis cinq ans, qui recouvrait l'est de la Maurétanie Sitifienne et le nord-ouest de la Numidie, ${ }^{207}$ où ils exploiteraient des terres appelées sortes Vandalorum, ${ }^{208}$ enlevées à des Romains, ce qui était déjà fait. En outre, l'empereur d'Orient, admettait implicitement qu'ils n'étaient pas des socii. S'il était avisé, il devait s'attendre à une rupture de ce contrat qui n'avait aucune valeur pour les Vandales. ${ }^{209}$ Plusieurs auteurs de l'Antiquité les ont traités de menteurs et, même s'ils faisaient partie du camp des victimes, ils n'ont pas eu tort.

\subsection{La prise de Carthage}

Les Vandales n'avaient donc accepté le traité de 435 que comme une pause. Quatre ans plus tard, en effet, ils s'emparaient de Carthage, la plus grande cité de l'Afrique, l'une des plus importantes villes de l'empire, après Rome et Constantinople, à peu près au niveau d'Alexandrie et d'Antioche. ${ }^{210}$

La date est établie avec une grande probabilité: ce fut le 14 des kalendes de novembre, soit le 19 octobre $439 .{ }^{211}$ Un texte place l'événement au 10 des kalendes,

204 Salvian. Gub. Dei 7.26, 50, 90, 91 et 94.

205 Ausbüttel 1991; voir notes suiv. Il n'y a pas eu de traité en 411.

206 Procop. Vand. 1.4.2; Prosp. Chron. 1321. Romanelli 1959, 655; Julien 1968, 237; Courtois 1955, 69; Francovich Onesti 2002, 36; Schwarcz 2004, 51; Merrills - Miles 2010, 61; Modéran 2014, 116. Le traité n'a pas été “signed" comme l'ont co-écrit nos savants collègues: dans l'Antiquité, on ne "signait" pas les traités.

207 Hattler, éd., 2009, 181.

208 Procop. Vand. 3.5.11. Merrills - Miles 2010, 61. Sur les sortes Vandalorum, voir plus haut.

209 Prosp. Chron. 1327, mentionne un traité de 437: c'est une confusion de sa part.

210 Romanelli 1959, 657-658; Lancel 1988, 652; Francovich Onesti 2002, 37; Berndt 2007, 135-141; Lusvarghi $2016,39$.

211 Hyd. 115-118; Laterculus regum Wandalorum et Alanorum, 2. Julien 1968, 237; Modéran 2014, 117-121. 
très probablement par erreur. ${ }^{212}$ L'affaire présentait quelque difficulté, parce qu'un nouveau rempart avait entouré l'agglomération en 425; c'est le mur de Théodose (Théodose II), qui semble avoir été bien conçu. ${ }^{213}$ Pour contourner l'obstacle, les Vandales recoururent à la ruse; ils agirent dolo comme disent les textes anciens. ${ }^{214} \mathrm{Le}$ mot choisi par les "Romains", dolus, est péjoratif; mais il recouvre en réalité une pratique bien généralisée à cette époque, comme on l'a dit, le stratagème. Par malheur pour nous, nous ignorons quelle astuce fut mise en œuvre à cette occasion.

Cette conquête entraîna plusieurs conséquences. D'abord, l'ordre moral des ariens fut imposé à toute l'Afrique et en particulier à sa capitale, où furent fermés les théâtres et les thermes, ce qui ne fut sans doute pas sans conséquences sur l'hygiène publique. ${ }^{215}$ Ensuite, nous savons, sans que les textes aient besoin de le dire (mais ils

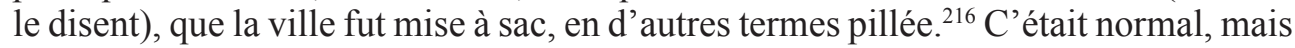
les barbares firent mieux puisqu'ils organisèrent une nouvelle vague d'exilés; Quodvultdeus fut alors chassé et il gagna Naples. ${ }^{217}$ Ce n'était d'ailleurs peut-être pas le meilleur choix, puisque Geiserich arma une flotte et dès 440 l'envoya piller la Sicile, en attendant de s'en prendre à l'Italie. ${ }^{218}$

Un nouveau traité fut conclu en 442; ce n'était pas un renouvellement du traité de 435, comme on l'a écrit, ${ }^{219}$ mais un texte qui dessinait une nouvelle carte de l'Afrique. Le roi vandale installait sa capitale à Carthage et, s'il abandonnait ses anciennes possessions, il recevait en échange de bien plus riches et plus vastes territoires, l'est de la Numidie, la Proconsulaire, la Byzacène et la Tripolitaine. ${ }^{220}$ Par la suite, son domaine d'influence s'étendit jusqu'en Maurétanie Tingitane et dans les Baléares, ${ }^{221}$ cependant que ses raids de pillage n'épargnaient ni la Sicile ni le sud de l'Italie. Ces actions offensives furent considérées comme de la piraterie par les victimes; les Vandales utilisaient sans aucun doute des marins africains, plus ou moins volontaires, pour le maniement des navires et ils se chargeaient eux-mêmes des combats.

\section{Conclusion}

L'histoire de la conquête de l'Afrique par les Vandales est un vaste sujet. Il n'était pas question de tout traiter ici et nous nous bornerons à rappeler quelques acquis qui paraissent essentiels et originaux pour l'aspect proprement militaire; nous chercherons même à restreindre ce rappel aux questions de tactique et de stratégie.

Pour la tactique, cette période correspond à un moment important, où de profonds changements s'amorcent (s'amorcent seulement). Chez les Vandales, l'infanterie reste la reine des batailles, mais l'archerie décline et la cavalerie prend son essor; ce mouvement n'a été achevé que plus tard.

\footnotetext{
212 Marcellinus comes, a. 439, 3.

213 Lancel 1988, 652 (et plan, 660).

214 Oros. Hist. 7.38.1; Hyd. 115; Cassiod. Chron. 1233; Bède, dans Chron. min. 3.481. Courcelle 1964, 130, a inventé un assaut; Francovich Onesti 2002, 37.

215 Le Bohec 2007b, 159.

216 Vict. Vit. 1.5 et 12.

217 Vict. Vit. 1.15.

218 Romanelli 1959, 659-660.

219 Romanelli 1959, 660; Lusvarghi 2016, 40.

220 Julien 1968, 238; Francovich Onesti 2002, 181.

221 Villaverde Vega 2006.
} 
Du côté des "Romains", on constate une invraisemblable médiocrité. Nous mettons des guillemets à leur nom pour deux raisons: ces soldats étaient recrutés très souvent chez les barbares, et ils ne méritaient pas ce nom, eu égard aux qualités de l'antiqua legio. Le seul point positif se trouve dans la poliorcétique: le siège d'Hippone a duré quatorze mois; pour prendre Carthage, les ennemis ont dû recourir à la ruse, au stratagème.

En ce qui concerne la stratégie, il convient de distinguer celles qui ont été appliquées en 429 et en 439.

En 429, le système défensif romain a été tourné; il avait été mis en place dès le Haut-Empire pour faire face à un ennemi venu du sud; or l'ennemi est venu du nord. La défense en profondeur propre au Bas-Empire aurait pu atténuer l'impact, mais les soldats étaient trop mauvais et leurs chefs trop incompétents pour qu'ils puissent en tirer parti.

Le roi Geiserich, pour sa part, a opté pour une stratégie offensive, sous forme d'une expédition en ligne droite; certes, il exposait son flanc droit, mais ses ennemis, là encore, n'ont pas été capables d'exploiter cet avantage. Ses troupes ont contourné le système défensif romain puis elles l'ont détruit sans rien mettre à la place.

En 439, les Vandales ont fait pire. En rasant les remparts urbains, pour anéantir toute tentative de résistance des populations afro-romaines, ils se sont privés d'une grande partie de leurs capacités défensives. En organisant une marine conçue pour le pillage uniquement, ils ont négligé les navires de combat, inutiles il est vrai devant l'absence de flotte militaire romaine digne de ce nom. Ils ont lourdement payé ces deux faiblesses un siècle plus tard, au moment de la reconquête byzantine. Mais c'est là une autre histoire.

\section{Bibliographie}

Aiello, V.

(2004): "I Vandali nel Mediterraneo e la cura del limes", AfrRom 15/1, 723-740.

(2005): "I Vandali nell'Africa romana: problemi e perspettive di ricerca", MedAnt 8/2, 547-569.

Arce J.

(2002): “Los Vándalos en Hispania (409-429 AD)”, AntTard 10, 75-85.

(2005): "Spain and the African Provinces in Late Antiquity", [in] K. Bowes - M. Kulikowski (éds.), Hispania in Late Antiquity, Current Perspectives (=Medieval and early modern Iberian world 24), Leiden, 341-368.

Ausbüttel, F. M. (1991): “Die Verträge zwischen den Vandalen und Römern”, RomBarb 11, $1-20$.

Beltrán Torreira, F. M. (1988): "Un testimonio de la invasión vándala del norte de África: Posidio de Calama y su Vita Augustini”, [in] Actas del Congreso Internacional 'El Estrecho de Gibraltar' (Ceuta 1989), Madrid, vol. I, 1115-1122.

Berndt, G. M. (2007): Konflikt und Anpassung. Studien zu Migration und Ethnogenese der Vandalen, Husum.

Berndt, G. M. - Steinacher, R. (éds.), (2008): Das Reich der Vandalen und seine (Vor-)Geschichten (=Forschungen zur Geschichte des Mittelalters 13), Vienne.

Bourgeois, Cl. (1980): “Les Vandales, le vandalisme et l'Afrique”, AntAfr 16, 213-228. 
Bravo Jiménez, S. (2002): "Iulia Traducta y Tingi: dos ciudades romanas en los confines del Imperio", [in] M. Khanoussi - P. Ruggeri - C. Vismara (éds.), L'Africa romana. Atti del XV convegno di studio. Ai confini dell'Impero: contatti, scambi, conflitti (Tozeur, 11-15 dicembre 2002), Roma, 651-672.

Brizzi, G. (1989): "Liv. XXIV, 46-47 e XXVI, 29-32: variazioni sul tema della fides romana", [in] Carcopino, Cartagine e altri scritti, Ozieri, 117-142.

Brüggemann, Th. (2003): Römer, Nomaden, Christen. Staat und Gesellschaft im spätantiker Nordafrika (3.-5. Jh. n. Chr.). Untersuchungen zur sozialen und politischen Entwicklung der nordafrikanischen Provinzen des Römischen Reiches im Kontext ihrer Christianisierung von der Tetrarchie bis zur Niederlage gegen die Vandalen, Jena.

Caliri, E. (2012): “Il prelievo fiscale nell'Africa vandala", AfrRom 19/2, 1141-1154.

Cameron, A. (2000): "Vandal and Byzantine Africa", Cambridge Ancient History 14, Cambridge, $552-560$.

Carucci, M. (2012): "Power Relationships between Vandals and Romans in Carthage", AfrRom 19/2, 1155-1166.

Castritius, H. (2007): Die Vandalen. Etappen einer Spurensuche, Stuttgart.

Cesa, M. (2001): "Roma e i Vandali nell'età di s. Agostino, L'adorabile vescovo di Ippona", [in] F. E. Consolino (éd.), Atti del Convegno di Paola (24-25 maggio 2000), Studi di filologia antica e moderna, 9, Rubbettino, 133-151.

Chalon, M. et alii (1985): "Memorabile factum. Une célébration de l'évergétisme des rois vandales dans l'Anthologie latine", AntAfr 21, 207-262.

Clover, F. M. (1993): The Late Roman West and the Vandals, Aldershot.

Coppolino, E. (2012): "Rex, dux, imperator: figure di potere "romanizzate" nella Mauretania tardoantica”, AfrRom 19/1, 1003-1012.

Courcelle, P. (1964³): Histoire littéraire des grandes invasions germaniques, Paris.

Courtois, Chr.

(1954): Victor de Vita et son ouvre, Alger.

(1955): Les Vandales et l'Afrique, Paris.

Diesner, H. J.

(1962): "Die Lage der nordafrikanischen Bevölkerung im Zeitpunkt der Vandaleninvasion", Historia 11, 97-111.

(1963): Kirche und Staat in spätrömischen Reich, Berlin.

(1966): Das Vandalenreich, Leipzig.

Divers auteurs (2002): L'Afrique vandale et byzantine (=AntTard 10), Turnhout.

Divers auteurs (2003): L'Afrique vandale et byzantine (=AntTard 11), Turnhout.

Divers auteurs (2006): L'Afrique vandale et byzantine (=AntTard 14), Turnhout.

Duval, N. (2002): “Deux mythes de l'iconographie de l'Antiquité tardive: la villa fortifiée et le 'chasseur vandale"', [in] J.-M. Carrié (éd.), Humana sapit. Études d'antiquité tardive offertes à Lellia Cracco Ruggini (=Bibliothèque de l'Antiquité Tardive 3), Turnhout, 333-340.

Francovich Onesti, N. (2002): I Vandali. Lingua e storia, Roma.

Gautier, E.-F. (1932): Genséric, roi des Vandales, Paris.

Gelarda, I. (2012): “Wentilseo e Mare Internum: dinamiche produttive e rapporti comerciali tra l'Africa vandala e il Mediterraneo", AfrRom 19/2, 1447-1469.

Gil Egea, M. E. (1998): África en tiempos de los Vándalos. Continuidad y mutaciones de las estructuras socio-políticas romanas, Alcalá de Henares.

Goetz, H. W. - Patzold, S. - Welwei, H. W. (éds.), (2007): Germani aetatis migrationis gentium. Excerpta e fontibus antiquis quae supersunt de Germanis a medio saeculo tertio 
usque ad annum CCCCLIII p. Chr., Pars altera, Die Germanen in der Völkerwanderung. Auszüge aus den antiken Quellen Über die Germanen von der Mitte des 3. Jahrhunderts bis zum Jahre 453 n. Chr., 2, Ausgewählte Quellen zur deutschen Geschichte des Mittelalters, 1, b, 2, Darmstadt.

Goffart, W.

(1980): Barbarians and Romans AD 418-584. The Techniques of Accomodation, Princeton.

(2012): "Le début (et la fin) des sortes Vandalorum", [in] Porena - Rivière (éds.), 2012, $115-128$.

González Salinero, R.

(2001): "La invasión vándala en los Sermones de Quodvultdeus de Cartago", Flor.llib. 12, 221-237.

(2002): Poder y conflicto religioso en el norte de África: Quodvultdeus de Cartago y los Vándalos (=Signifer. Graeco-romanae religionis electa collectio 10), Madrid.

(2014): "Quodvultdeus y la resistencia católica a la conquista vándala del norte de África”, [in] G. Bravo - R. González Salinero (éds.), Conquistadores y conquistados: relaciones de dominio en el mundo romano (=Signifer, Monografías y Estudios de antigüedad griega y romana 43), Madrid-Salamanca, 325-335.

Gozalbes Cravioto, E. (2001): "La supuesta ubicación de Iulia Traducta en Tarifa”, Aljaranda 21, 12-15.

Gwynn, D. M. (2012): “Episcopal leadership", [in] S. F. Johnson (éd.), The Oxford Handbook of Late Antiquity, Oxford, 876-915 (http://dx.doi.org/10.1093/oxford$\mathrm{hb} / 9780195336931.001 .0001)$.

Hattler, C. (éd.), (2009): Das Königreich der Vandalen. Erben des Imperiums in Nordafrika, Mayence.

Hays, G. (2004): “Romuleis libicisque litteris: Fulgentius and the 'Vandal Renaissance”, [in] Mérrills (éd.), 2004, 101-132.

Hettinger, A. (2001), "Migration und Integration. Zu den Beziehungen von Vandalen und Romanen im Norden Afrikas", FMS 35, 121-143.

Julien, Ch.-A. (1968²): Histoire de l'Afrique du Nord, 1, Des origines à la conquête arabe, Paris.

Kleemann, J. (2002): “Quelques réflexions sur l'interprétation ethnique des sépultures habillées considérées comme vandales", [in] Divers auteurs, 2002, 123-129.

Kouznetsov, V. - Lebedynsky, I. (2005²): Les Alains, cavaliers des steppes, seigneurs du Caucase, Paris.

Kuhoff, W. (2012): “Das spätrömische Afrika und seine Militärbefehlshaber”, AfrRom 19/1, 541-564.

Lambert, D. (2000): “The Barbarians in Salvian's De gubernatione Dei”, [in] S. Mitchell G. Greatrex (éds.), Ethnicity and Culture in Late Antiquity, London, 103-115.

Lancel, S.

(1988): "Victor de Vita et la Carthage vandale", AfrRom 6, 649-661.

(1999): Saint Augustin, Paris.

Lançon, B. (2015): “L’Afrique vandale comme objet de chronique”, [in] Wolff (éd.), 2015, 39-52.

Laporte, J.-P. (2005): “Les Vandales, l'Afrique et les Maures”, [in] M. Heijmans (éd.), La Méditerranée et le monde mérovingien, Aix-en-Provence, 271-280.

Lassère, J.-M. (2015): Africa, quasi Roma (256 av. J.-C- 711 apr. J.-C.), Paris.

Le Bohec, Y.

(2006): L'armée romaine sous le Bas-Empire, Paris. 
(2007a): “L'armée romaine d'Afrique de 375 à 439: mythes et réalités", [in] A. Lewin - P. Pellegrini (éds.), The Late Roman Army in the Near East from Diocletian to the Arab Conquest, Proceedings of a Colloquium held at Potenza, Acerenza and Matera, Italy (May 2005), (=BAR International Series 1717), Oxford, 431-441.

(2007b): "Le visage de la guerre pour les civils dans l'Antiquité. Victor de Vita et les Vandales", RSA 37, 153-166.

(2007c): L'armée romaine en Afrique et en Gaule (=Mavors 14), Stuttgart.

(2009): “Africa in der späten Kaiserzeit”, [in] Das Königreich der Vandalen: Erben des Imperiums in Nordafrika, Mainz, 65-75.

(2013): Histoire de l'Afrique romaine (146 avant J.-C. - 439 après J.-C.), Paris.

(2014): La guerre romaine: 58 avant J.-C. - 235 après J.-C., Paris.

(2015): "Sur la traduction de magister militum, 'général' ou 'commandant", Latomus 74/1, 214-217.

(2016): "Les limites de la renaissance dans l'empire romain de la fin du IV à la fin du Ve siècle", [in] M. Slavova - N. Sharankov (éds.), Monuments and Texts in Antiquity and beyond. Essays for the centenary of Georgi Mihailov (=Studia Classica Serdicensia V), Sofia, 33-43.

Le Gall, J. (1936): “L’itinéraire de Genséric", $R P h$ 10, 268-273.

Leone, A. (2007): Changing Townscapes in North Africa from Late Antiquity to the Arab Conquest (=Munera 28), Bari.

Lepelley, Cl. (2005): “Deux ruptures dans l'histoire de l'Afrique romaine: les Flaviens et les Vandales", Pallas 68, 49-62.

López Quiroga, J. - Martínez Tejera, A. M. - Morín de Pablos, J. (éds.), (2006): Mesa redonda hispano-francesa. Gallia e Hispania en el contexto de la presencia germánica (ss. $V$ VII). Balance y perspectivas (Universidad Autónoma de Madrid - MAR de la Comunidad de Madrid, 19-20 de diciembre 2005), (=BAR International Series 1534), Oxford.

Lusvarghi, M. (2016): "Lo spostamento dei Vandali in Africa. Problematiche e considerazioni fino alla presa di Cartagine", Rivista di Studi Militari 5, 29-43.

MacDowall, S. (2016): The Vandals, Conquerors of the Roman Empire, Croydon.

Marrou, H. (1967): "La valeur historique de Victor de Vita", CT 15, 205-208.

Maurin, L. (1967): “Thuburbo Maius et la paix vandale”, CT 15, 225-254.

Merrills, A. H. (éd.), (2004): Vandals, Romans and Berbers. New Perspectives on Late Antiquity, Aldershot.

Merrills, A. - Miles, R. (éds.), (2010): The Vandals, Chichester.

Milner, F. (1955): "Vandalen", RE, A 1, VIII col. 298-335.

Mkacher, A. (2015): “L'historiographie de l'Afrique vandale”, [in] Wolff (éd.), 2015, 93-106.

Modéran, Y.

(2002): "Les Vandales et la chute de Carthage", [in] C. Briand - S. Crogiez (éds.), Afrique du Nord antique et médiévale: mémoire, identité et imaginaire, Rouen, 97-132.

(2003a): Les Maures et l'Afrique romaine (=Bibliothèque de l'École française de Rome 314), Rome.

(2003b): "Une guerre de religion: les deux Églises d'Afrique à l'époque vandale", AntTard $11,21-44$.

(2006): “L'Afrique romaine à la veille de l'invasion vandale: pourquoi l'effondrement?", [in] López Quiroga - Martínez Tejera - Morín de Pablos (éds.), 2006, 61-76.

(2012): “Confiscations, expropriations et redistributions foncières dans l'Afrique vandale", [in] Porena - Rivière (éds.), 2012, Roma, 129-156.

(2014): Les Vandales et l'empire romain, Paris. 
Mommsen, Th. (éd.), (1898): Chronica minora, 3, Berlin.

Müller, C. (éd.), (1885): Fragmenta historicorum graecorum, 4, Paris.

Neri, C. (2008): "La fuga di fronte al pericolo. Opportunità politica o esempio morale? Possidio, Vita Augustini, 30", AfrRom 16/2, 959-975.

Perroy, É. (1954): Royaumes et sociétés barbares du V $V^{\mathrm{e}}$ au VIII siècle, Paris.

Pingel, V. (2006): “Celtic German Archaeology”, [in] Brill New Pauly, Classical Tradition I, Leiden, 735-740.

Pizzica, M. (1982-1983): "Possidio e la caduta di Ippona", RomBarb 7, 181-199.

Pohl, W.

$\left(2000^{2}\right)$ : Die Germanen, München.

(2002): Die Völkerwanderung. Eroberung und Integration, Stuttgart.

(2004): “The Vandals: Fragments of a Narrative", [in] Merrills (éd.), 2004, 31-48.

Porena, P. - Rivière, Y. (éds.), (2012): Expropriations et confiscations dans les royaumes barbares (=CÉFR 470), Roma.

Rapp, C. (2000): "The Elite Status of Bishops in Late Antiquity in Ecclesiastical, Spiritual, and Social Contexts", Arethusa 33, 379-399 (http://dx.doi.org/10.1353/are.2000.0022).

Romanelli, P. (1959): Storia delle province romane dell'Africa, Rome.

Russo, C. A. (2012): "Insediamenti cenobitici e trasformazione del paesaggio nell'Africa tardoantica", AfrRom 19/1, 905-917.

Schwarcz, A. (2004): "The Settlement of the Vandals in North Africa”, [in] Merrills (éd.), 2004, 49-57.

Strzelczyk, J. (2003): "Die Vandalen auf dem Weg nach Nordafrika”, [in] Die Vandalen. Die Könige. Die Eliten. Die Krieger. Die Handwerker, Nordstemmen, 203-246.

Tedesco, P. (2012): "Sortes Vandalorum: forme d'insediamento nell'Africa post-romana", [in] Porena - Rivière (éd.), 2012, 157-224.

Tizzoni, M. L. (2014): "Dracontius and the Wider World: Cultural and Intellectual Interconnectedness in Late Fifth-Century Vandal North Africa", Networks and Neighbours 2/1, 96-117.

Todd, M. (2000): Die Germanen, Stuttgart.

Villaverde Vega, N.

(2001): Tingitana en la Antigüedad Tardía, siglos III-VII. Autoctonía y romanidad en el extremo occidente mediterráneo (=Real Academia de la Historia. Publicaciones del Gabinete de Antigüedades. Bibliotheca Archaeologica Hispana 11), Madrid.

(2006): "Datos literarios y arqueológicos sobre el dominio vándalo en Tingitana y Baliares (siglos V-VI)”, [in] López Quiroga - Martínez Tejera - Morín de Pablos (éds.), 2006, $79-88$.

(2008): "El reino vándalo-africano y la persistencia mercantil del estrecho septegaditano (mitad s. V - primer tercio s. VI)", MM 49, 425-450.

Von Rummel, Ph.

(2002): "Habitus Vandalorum? Zur Frage nach einer gruppenspezifischen Kleidung der Vandalen in Nordafrica", [in] Divers auteurs, 2002, 131-141.

(2003): "Zum Stand der afrikanischen Vandalenforschung”, AntTard 11, 13-19.

(2005): “Les Vandales ont-ils porté en Afrique un vêtement spécifique?”, [in] La Méditerranée et le monde mérovingien: témoins archéologiques (Actes des 23es journées internationales d'archéologie mérovigienne, Arles, 11-13 octobre 2002), (=Bulletin Archéologique de Provence, Supplément 3), Aix-en-Provence, 281-291.

(2009): "Fragen an die Vandalen. Zur Situation der Vandalenforschung”, Das Königreich der Vandalen, 27-31. 
Vössing, K.

(2012): "Hippo Regius und das Schicksal des toten Augustinus. Datierungen und Hypothesen", Hermes 140/2, 202-229.

(2015): "Vandalen und Goten", [in] Wolff (éd.), 2015, 11-37.

Wheeler, E. L. (1988): Stratagem and the vocabulary of military trickery (=Mnemosyne Suppl. 108), Leiden.

Wijnendaele, J. W. P. (2015): The last of the Romans. Bonifatius, warlord and comes Africae, London.

Wilczynski, M. (1993): "Die Organisation der Armee des Königsreiches der Wandalen und Alanen in Africa", Rocznik Naukowo-Dydaktyczny wsp w Krakowie, Prace Historyczne 16, 27-41 [en polonais, résumé en allemand].

Wolff, É. (éd.), (2015): Littérature, politique et religion en Afrique vandale (=Institut d'Études Augustiniennes. Série Antiquité 200), Paris. 